\title{
EL DERECHO A LA PROTECIÓN DE LA SALUD EN EL TRABAJO FRENTE A LOS RIESGOS DEL COVID-19
}

\author{
Bárbara Torres García \\ Doctoranda de la Universidad de Santiago de Compostela
}

\begin{abstract}
La imprescindible contención y control del COVID-19, coexistente con el necesario reinicio de la actividad productiva y económica, ha originado la necesidad de actualizar y adaptar las políticas preventivas a la presencia de aquel en el entorno laboral. Todo plan de prevención deberá partir de una actualización de la evaluación del nuevo riesgo generado, para, luego, en función de las posibilidades y recursos empresariales, establecer las medidas profilácticas más adecuadas respecto de cada puesto.
\end{abstract}

The essential containment and control of COVID-19, coexisting with the necessary restart of productive and economic activity, has led to the need to update and adapt preventive policies to its presence in the work environment. All prevention plans must start with an update of the new risk evaluation, and then, depending on the possibilities and business resources, establish the most appropriate prophylactic measures for each position.

Title: the right to health protection at work facing the risks of covid-19

Palabras clave: COVID-19, derecho a la vida e integridad física y moral, prevención de riesgos, evaluación.

Keywords: COVID-19, right to life and physical and moral integrity, risk prevention, evaluation.

IUSLabor 1/2021, ISSN 1699-2938, p. 5-41

DOI. 10.31009/IUSLabor.2021.i01.01

Fecha envío: 1.9.2020 | Fecha aceptación: 25.1.2021 


\section{Sumario}

1. Introducción

2. La configuración del deber de protección del empresario: rasgos generales

3. La necesaria adaptación de las políticas preventivas a los riesgos generados por el COVID-19

4. La necesaria protección del trabajador en régimen de teletrabajo

5. La adopción de medidas organizativas, higiénicas y de control en el centro de trabajo

6. Conclusiones

7. Bibliografía 


\section{Introducción}

En septiembre de 2019, la Organización Mundial de la Salud (en adelante, OMS) publicaba un informe anual sobre la preparación de la humanidad frente a las emergencias sanitarias, en el que ya declaraba que el espectro de una emergencia sanitaria mundial se vislumbraba peligrosamente en el horizonte y que el mundo no estaba preparado ${ }^{1}$. Solo tres meses más tarde de su publicación, se diagnostica el primer caso de COVID-19 (enfermedad vírica provocada por el SARS-Cov-2), en la región de Wuhan (China). Tal y como pronosticaba el referido dossier, la humanidad no estaba, ni está, capacitada para hacer frente a una nueva pandemia y, menos aún, de tal magnitud como la que estamos viviendo. La Segunda Edición del "Reglamento Sanitario Internacional de la OMS" de 2005, aprobado en Ginebra en 2008 [en adelante, RSI (2005)] ${ }^{2}$, establecía, en su artículo 5, el compromiso de cada Estado parte de desarrollar, reforzar y mantener la capacidad de detectar, evaluar y notificar nuevos brotes epidemiológicos. Aunque fueron ciento noventa y seis países los que se comprometieron, un informe elaborado para la Global Preparedness Monitoring Board (en adelante, GPMB), de septiembre de $2019^{3}$, muestra que, en 2018, solo un tercio de los Estados firmantes contaban con las capacidades requeridas por el RSI (2005). Dicha memoria concluía que la mayoría de los sistemas nacionales de salud serían incapaces de hacer frente a una afluencia importante de pacientes infectados por un patógeno respiratorio (y, en efecto, eso fue lo que ocurrió en la práctica).

A la vista de lo recién expuesto, lo cierto es que el desarrollo y la propagación del COVID19 ha puesto en duda no solo los sistemas sanitarios de todos y cada uno de los Estados (ya sean europeos o no), sino también los sistemas sociales, económicos y, por supuesto, las estructuras laborales de aquellos. Ante esta situación, la Organización Internacional del Trabajo (en adelante, OIT), en un informe de marzo de $2020^{4}$, ha declarado la necesidad de adoptar políticas basadas en la estimulación de la economía y el empleo, en

\footnotetext{
${ }^{1}$ Ver OMS: "Informe anual sobre la preparación mundial para las emergencias sanitarias", de septiembre de 2019. Disponible en el siguiente enlace:

https://apps.who.int/gpmb/assets/annual_report/GPMB_Annual_Report_Spanish.pdf

${ }^{2}$ La finalidad de dicho Reglamento era la de "prevenir la propagación internacional de enfermedades, proteger contra esa propagación, controlarla y darle una respuesta de salud pública proporcionada y restringida a los riesgos para la salud pública y evitando, al mismo tiempo, las interferencias innecesarias con el tráfico y el comercio internacionales" (artículo 3). Disponible en el siguiente enlace: https://www.who.int/ihr/IHR_2005_es.pdf

${ }^{3}$ Ver OMS: "Thematic Paper on the Status of Country Preparedness", de 25 de septiembre de 2019. Disponible en el siguiente enlace: https://apps.who.int/gpmb/assets/thematic_papers/tr-2.pdf

${ }^{4}$ Ver OIT: "COVID-19 and the world of work: Impact and policy responses", de 18 de marzo de 2020. Disponible en el siguiente enlace:

https://www.ilo.org/wcmsp5/groups/public/--_dgreportdcomm/documents/briefingnote/wcms_738753.pdf
} 
el mantenimiento de los puestos de trabajo y en la debida protección de los trabajadores. Solo mediante esta línea tridimensional se logrará un desarrollo sostenido y una recuperación equitativa, sin poner en peligro el trabajo decente.

En respuesta a las exigencias de la OIT, se promulga, en un período inicial de excepcionalidad, el Real Decreto-ley 8/2020, de 17 de marzo, de medidas urgentes y extraordinarias para hacer frente al impacto económico y social del COVID-19 (en adelante, $\mathrm{RD} 8 / 2020)^{5} \mathrm{y}$, posteriormente, ya en la primera fase de recuperación, el Real Decreto-ley 18/2020, de 18 de mayo, de medidas sociales en defensa del empleo (en lo siguiente, RD 18/2020). En todo caso, en ambos textos legales, se adoptan disposiciones tendentes a mantener, proteger e, incluso, fomentar el trabajo. En esta línea, se establece el derecho del trabajador a solicitar la adaptación y la reducción de jornada para hacer frente a las nuevas situaciones personales y familiares derivadas del nuevo panorama social, la posibilidad de suspensión (y no de extinción) de contratos laborales con la finalidad de evitar mayores consecuencias económicas a las empresas, la interrupción del cómputo de la duración máxima de los contratos temporales y, finalmente, como disposición a destacar, se impone el carácter preferente del teletrabajo. Todas y cada una de las medidas adoptadas y establecidas tienen una finalidad clave, que se identifica en la necesaria continuidad del empleo. Ahora bien, si este es el objetivo, el mismo debe alcanzarse manteniendo, adaptando e, incluso, mejorando, la protección del trabajador frente a los nuevos riesgos laborales surgidos con ocasión del COVID-19.

En un contexto de recuperación, es clave no solo la continuidad del trabajo, sino también, la protección de la salud de los trabajadores durante el desempeño de sus responsabilidades profesionales. El artículo 15 de la Constitución Española (en adelante, $\mathrm{CE}$ ) reconoce el derecho de toda persona a la vida y a la integridad física y moral. Se trata de un derecho que, siendo reconocido con carácter general a todo ciudadano (por el mero hecho de ser persona), en el ámbito laboral, recibe la denominación de derecho fundamental inespecífico, por cuanto no nace de la relación de trabajo, sino que, dado su carácter erga omnes, se impone a ella y a la prestación de servicios ${ }^{6}$. A la hora de

\footnotetext{
${ }^{5}$ Completado por el Real Decreto-ley 9/2020, de 27 de marzo, por el que se adoptan medidas complementarias, en el ámbito laboral, para paliar los efectos derivados del COVID-19.

${ }^{6} \mathrm{La}$ STC 62/2007, de 27 de marzo, establece que "en efecto, en las relaciones de trabajo nacen una serie de derechos y deberes de protección y prevención, legalmente contemplados, que reclaman una lectura a la luz de la Constitución, pues no cabe desconectar el nivel jurídico constitucional y el infraconstitucional en estas materias, toda vez que la Constitución reconoce derechos fundamentales como la vida e integridad física (artículo $15 \mathrm{CE}$ ), lo mismo que el derecho a la salud (artículo 43), y ordena a los poderes públicos a velar por la seguridad e higiene en el trabajo (artículo 40.2 CE)". En relación con ello, GONZÁLEZ ORTEGA, Susana, "La seguridad e higiene en el trabajo en la Constitución", Revista de Política Social, núm. 121, 1979, p. 200, cuando manifiesta que "el artículo 15 de la Constitución permitirá la defensa de
} 
configurar este derecho, el ordenamiento jurídico español lo hace de manera ambiciosa, otorgándole su carácter fundamental y un nivel máximo de protección. Un ámbito protector que parte de dos principios rectores vitales y que se concretan en la necesaria obligación, de los poderes públicos, de proteger la salud y velar por la seguridad e higiene laboral (artículos 40.2 y 43 CE). El legislador de 1978, dada la importancia del bien jurídico protegido (que no era otro que la vida e integridad física y moral del trabajador, y, por ello, su salud) ${ }^{7}$, optó por la configuración de un doble nivel de garantía. En este sentido, se estableció una protección integral del derecho a la salud y seguridad laboral, reconociéndole su carácter de fundamental (artículo $15 \mathrm{CE}$ ) e imponiendo a la Administración la adopción de políticas de protección (artículos 40.2 y $43 \mathrm{CE}$ ), que se desarrollaron en la Ley 31/1995, de 8 de noviembre, de prevención de riesgos laborales (en adelante, LPRL).

Si se parte del carácter fundamental del derecho a la salud laboral (inescindible del derecho a la vida e integridad física, del artículo $15 \mathrm{CE})^{8}$, es obvia la necesaria protección

la integridad física y moral del individuo, de su vida, frente a cualquier agresión posible, lo que en el contexto de la relación laboral va a suponer la potenciación de tal derecho respecto a los deberes $u$ obligaciones que para el trabajador se deriven del contrato y su función como límite a los poderes del empleador". Ver, del mismo modo, LÓPEZ INSUA, Belén del Mar: "derecho a la vida e integridad física", en VV.AA., MONEREO PÉREZ, José Luís, VILA TIERNO, Francisco, y ÁLVAREZ CORTES, Juan Carlos (directores) y LÓPEZ INSUA, Belén del Mar, Derechos laborales fundamentales específicos, Granada, Comares, 2020, pp. 501-537; SAN MARTÍN, MAZZUCCONI, Carolina, "Derecho a la Vida e integridad personal; la seguridad y salud en el trabajo", Revista del Ministerio de Empleo y Seguridad Social, núm. 108, 2014, pp. 91-108, PALOMEQUE LÓPEZ, Manuel Carlos, "El derecho constitucional del trabajador a la seguridad en el trabajo", Actualidad Laboral, núm. 1, 1992, pp. 37-44.

${ }^{7}$ La STC 53/1985, de 11 de abril, declara, a estos efectos, que "el derecho a la vida, reconocido y garantizado en su doble significación física y moral por el artículo 15 de la Constitución, es la proyección de un valor superior del ordenamiento jurídico constitucional -la vida humana- y constituye el derecho fundamental esencial y troncal en cuanto es el supuesto ontológico sin el que los restantes derechos no tendrían existencia posible". Ciertos autores, dada la importancia del derecho, llegan incluso a declarar que "la conceptuación como 'derecho a la vida' no es técnicamente correcta. La vida pre-existe al derecho como realidad, con contenido complejo. Al igual que el derecho a la salud, el reconocimiento constitucional no es más que una máxima exigencia de protección. El derecho a la vida en realidad, debería ser el derecho a la protección a la vida, tal y como reconoce el artículo 2.1 CECH y normativa internacional", en ESQUERRA ESCUDERO, Luís: "Contenido y extensión del artículo 15. Incidencia en el ámbito laboral”, en VV.AA., ESQUERRA ESCUDERO, Luís (coordinador), RIVAS VALLEJO, Pilar, y AGUSTÍ MARAGALL, Joan, Estudios sobre el derecho a la vida e integridad física y moral en el ámbito laboral, Barcelona, Atelier Libros Jurídicos, 2010, p. 18.

${ }^{8}$ Ver, TORRES GARCÍA, Bárbara, "Derecho a la protección de la salud y seguridad en el empleo y su naturaleza de derecho fundamental en el ordenamiento español", texto original (en prensa). En contra de esta interpretación se opone la mayoría de la doctrina y jurisprudencia constitucional, al entender que el derecho fundamental a la vida (artículos15 CE) y el derecho a la salud y seguridad laboral (artículos 40.2 y $43 \mathrm{CE}$ ) son completamente estancos, sin ningún tipo de interrelación. Estos autores alegan que una cosa 
que debe otorgársele, máxime en un contexto como el actual. El artículo 14 LPRL establece el derecho de todo trabajador a una protección eficaz en materia de seguridad y salud en el trabajo, disponiendo que el empresario (titular del deber de protección) deberá "desarrollar una acción permanente de seguimiento de la actividad preventiva", con el fin de adaptar las medidas de prevención a las modificaciones que puedan experimentar las circunstancias que incidan en la realización del trabajo. El COVID-19 plantea, en este ámbito, la necesidad de adaptar las políticas de prevención a los nuevos riesgos derivados de su expansión, desarrollo y posible contagio. El empresario, como responsable del deber de protección, está obligado a hacer frente a todos estos nuevos peligros, actualizando la evaluación de los riesgos a los que están expuestos sus empleados y, en función de estos, renovar la planificación preventiva.

\section{La configuración del deber de protección del empresario: rasgos generales}

El artículo 16 del Convenio núm. 155 de la OIT, de 22 de junio de 1989, establece que "deberá exigirse a los empleadores que, en la medida en que sea razonable y factible, garanticen que los lugares de trabajo, la maquinaria, el equipo y las operaciones y procesos que están bajo su control sean seguros y no entrañen riesgo". A nivel europeo, la Directiva 89/391/CEE del Consejo, de 12 de junio de 1989, relativa a la aplicación de medidas para promover la mejora de la salud y seguridad de los trabajadores (en adelante, Directiva 89/391/CEE), en su artículo 6, impone al empresario la obligación de adoptar "las medidas necesarias para la protección de la seguridad y de la salud de los trabajadores, incluidas las actividades de prevención de los riesgos profesionales, de información y de formación". El ordenamiento jurídico español, al trasponer las previsiones anteriormente citadas en el artículo 14 LPRL, reconoce el derecho del trabajador a la salud laboral ${ }^{9}$, a la vez que el correlativo deber de protección del empleador "mediante la integración de la actividad preventiva en la empresa".

es que, si bien un determinado derecho regulado por una norma infraconstitucional (ley ordinaria) puede tener como antecedente un derecho fundamental, no es menos cierto que su regulación no constituye el desarrollo directo del precepto constitucional. En otras palabras, una cosa es que los artículos 40.2 y $43 \mathrm{CE}$ (y, por tanto, la propia LPRL) puedan basarse en el derecho a la vida del artículo $15 \mathrm{CE}$, y otra distinta es que aquellos sean desarrollo directo del derecho fundamental. En este sentido, MARTÍN HERNÁNDEZ, María Luisa, "El derecho de los trabajadores a la seguridad y salud en el trabajo", Madrid, Consejo Económico y Social, 2006, pp. 59-89.

${ }^{9}$ En el mismo sentido, el artículo 4.2.d), del Real Decreto Legislativo 2/2015, de 23 de octubre, por el que se aprueba el texto refundido de la Ley del Estatuto de los Trabajadores (en adelante, ET), establece el derecho del trabajador a "su integridad física y a una adecuada política de prevención de riesgos laborales". Paralelamente, el artículo 19.1 ET reconoce, al igual que el artículo 14.1 LPRL, que "el trabajador en la prestación de sus servicios tendrá derecho a una protección eficaz en materia de seguridad y salud en el trabajo". 
De esta forma, se crea un deber general para el empresario de garantizar la seguridad y salud (y, por tanto, la integridad física y moral) del trabajador, en "todos los aspectos relacionados con el trabajo", mediante la "adopción de cuantas medidas sean necesarias" y el desarrollo de "una acción permanente de seguimiento de la actividad preventiva, con el fin de perfeccionar de manera continua las actividades de identificación, evaluación y control de los riesgos". A su vez, se debe disponer "lo necesario para la adaptación de las medidas de prevención a las modificaciones que puedan experimentar las circunstancias que incidan en la realización del trabajo". De la literalidad de este artículo 14 LPRL, se deduce, con claridad, que la actividad preventiva viene referida a cualquier aspecto relacionado con el trabajo. Se impone, así, la obligación de prevenir y proteger al trabajador frente a cualquier peligro al que pudiera exponerse por o con ocasión del desarrollo de su prestación asalariada.

A la hora de determinar lo que se entiende como "factor riesgo", al que debe hacer frente diligentemente el empresario mediante políticas preventivas y de protección, la LPRL es clara al disponer que, en dicho concepto, queda englobada toda condición de trabajo "que pueda tener una influencia en la generación de riesgos para la seguridad y la salud del trabajador" (artículo 4.7 LPRL). De este modo, el empresario se encuentra obligado a planificar e integrar una actividad protectora, ya no solo frente a los riesgos laborales tradicionales (como la enfermedad o accidente profesional derivada del manejo de instrumentos de trabajo o de las condiciones del lugar de prestación de servicios, entre otros), sino, también, frente a los denominados "nuevos riesgos" o "riesgos emergentes" (tales como, los riesgos psicosociales, los derivados de la forma de organización del trabajo y la implantación de las nuevas tecnologías, los de carácter ergonómico y otros similares). Así pues, debiendo aquel prevenir los riesgos derivados de cualquier condición de trabajo, se puede afirmar que el deber de protección constituye una actividad integral que deberá, en todo caso, dirigirse a evitar los riesgos, evaluarlos, adaptar el trabajo a la persona (y no al revés, como ocurre en numerosas ocasiones), tener en cuenta la evolución de la técnica, sustituir lo peligroso por lo que entrañe poco peligro, planificar la prevención, anteponer la protección colectiva a la individual y facilitar las debidas instrucciones a los trabajadores (artículo 15.1 LPRL). A este respecto, el Tribunal Supremo llegó a declarar que, "como también concluye la doctrina científica, el deber de protección del empresario es incondicionado y, prácticamente, ilimitado"10.

Si bien se reconoce como un deber completo e ilimitado, que debe garantizar la salubridad de las condiciones de trabajo en sentido amplio, cabe precisar que el deber empresarial de protección no siempre supone la existencia de riesgo cero. El empresario, en

\footnotetext{
${ }^{10}$ STS, Sala de lo Social, de 8 de octubre de 2001 (RJ/2002/1424), reproducida posteriormente por la STS, Sala de lo Social, de 26 de mayo de 2009 (RJ/2009/3256).
} 
cumplimiento de su obligación, debe evitar todo tipo de riesgo, pero, cuando ello no sea posible (pues la propia actividad ya implica peligro, o porque el mismo existe con independencia de la prestación de servicios), aquel deberá minimizar los efectos de este sobre la persona del trabajador. La actividad preventiva debida por el empleador, en contraposición del derecho del trabajador a una protección eficaz, no se traduce, siempre, en un deber de erradicar todos y cada uno de los posibles peligros existentes en su organización empresarial, sino en la diligente gestión e integración de todas las medidas necesarias para eliminar dichos riesgos o, cuanto menos, reducirlos al mínimo ${ }^{11}$. La LPRL no impone al empresario el deber de proporcionar una seguridad absoluta (riesgo cero), pues "es un deber imposible de cumplir en todo caso y, por tanto, jurídicamente inexigible" (artículo 1272 Código Civil)"12.

Así las cosas, se trata de un deber general y completo, un deber de medios ${ }^{13}$, y no de resultados, pero que, en todo caso, es permanente y de adaptación variable ${ }^{14}$. En el cumplimiento del mismo, no es loable que el empresario adopte unas medidas de seguridad estándares aplicables a la generalidad de los trabajadores y que permanezcan en el tiempo, ajenas a la evolución de la técnica y de la ciencia. Su deber de protección le exige una constante actualización de las medidas preventivas a los nuevos riesgos generados, así como la adopción de nuevas políticas precautorias, más eficaces, frente a los peligros existentes. En sentido, el ya citado artículo 14 LPRL relaciona el deber de protección del empleador con el cometido de "perfeccionar, de manera continua, las actividades de identificación, evaluación y control", adaptando, de ser necesario, las medidas de prevención a las nuevas circunstancias que incidan en la realización del trabajo. A estos efectos, un comportamiento pasivo del empresario, permaneciendo ajeno a cualquier condición que pueda afectar a la integridad física o moral del trabajador y manteniendo, por tanto, inalterada la política preventiva, a pesar de los nuevos peligros

\footnotetext{
${ }^{11}$ En este sentido, el artículo 4.1 LPRL define la actividad preventiva como "el conjunto de actividades o medidas adoptadas o previstas en todas las fases de la actividad de la empresa, con el fin de evitar o disminuir los riesgos derivados del trabajo".

${ }^{12}$ MARTÍN HERNÁNDEZ, María Luisa, op. cit., p. 192.

${ }^{13}$ De esta forma, LOZANO LARES, Fernando.: "El contenido y alcance de la obligación general de seguridad y, salud laboral”, Trabajo y Derecho, núm. 70, 2020, p. 6, indica que es "excesivo considerar el deber de seguridad como una obligación de resultado porque, si bien, es evidente, prima facie, que al trabajador lo que le interesa es el resultado (salud o seguridad), al empresario no puede exigírsele más que una determinada conducta, aunque se trata de una obligación de medio amplísima ya que, como hemos visto, no se trata solamente de cumplir las medidas legalmente previstas sino de poner todos los medios necesarios para que no se produzcan daños".

${ }^{14}$ PALOMEQUE LÓPEZ, Manuel Carlos, "El deber del empresario de protección de los trabajadores, frente a los riesgos laborales", Revista general del Derecho del Trabajo y de la Seguridad social, núm. 8, 2005, p. 4. Disponible en el siguiente enlace:

https://www.iustel.com/v2/revistas/detalle_revista.asp?id_noticia=403831\&d=1\&
} 
introducidos, puede tipificarse como una conducta sancionable, capaz de generar responsabilidades administrativas, penales o civiles ${ }^{15}$.

A mayores, no es suficiente con que el empresario lleve a cabo una actividad protectora individual, desconectada de la organización empresarial, sino que, por imperativo del artículo 5.5 LPRL, una política precautoria en esta materia "deberá promover la integración eficaz de la prevención de riesgos en el sistema de gestión de la empresa" 16. El trabajador, en la realización de su prestación asalariada, no solamente se encuentra expuesto a los peligros derivados de sus condiciones de trabajo, sino a todos aquellos originados por la propia organización empresarial. En la realización de las encomiendas profesionales, los trabajadores interactúan, se relacionan y se complementan, generando peligros que no solo afectan a un sujeto, sino a la totalidad de la plantilla. De esta forma, no resultaría eficaz la adopción aislada de medidas de seguridad, pues lo conveniente (y legalmente obligatorio) es la adopción de una actividad preventiva que integre los riesgos a los que se expone la colectividad de los trabajadores, aprobando medidas dirigidas a alcanzar el mayor grado de protección global. En este sentido, el empresario no cumple con su deber de protección cuando adopta medidas preventivas que, aun siendo adecuadas, se establecen de manera independiente frente a cada trabajador y a cada uno de los riesgos existentes. Por ello, para entender observado tal deber, aquel está obligado a establecer un plan de prevención de riesgos laborales (artículo 16 LPRL). En otras palabras, el empleador debe desarrollar una actividad integradora, en la que, una vez analizados los riesgos a los que se exponen los trabajadores, se contemplen los instrumentos imprescindibles para asegurar la salubridad de las condiciones laborales.

\footnotetext{
${ }^{15}$ El artículo 42 LPRL establece que "el incumplimiento por los empresarios de sus obligaciones en materia de prevención de riesgos laborales dará lugar a responsabilidades administrativas, así como, en su caso, a responsabilidades penales y a las civiles", y que "las responsabilidades administrativas que deriven del procedimiento sancionador serán compatibles con las indemnizaciones por los daños y perjuicios causados y de recargo de prestaciones económicas del sistema de la Seguridad Social". Véase, a estos efectos, CASAS BAAMONDE, María Emilia, "Derecho público y salud laboral: el régimen jurídico sancionador", Derecho y salud, vol. 4, núm. 1, 1996, pp. 91-124.

${ }^{16}$ En este punto, el apartado quinto de la exposición de motivos de la LPRL dispone que: "la protección del trabajador frente a los riesgos laborales exige una actuación en la empresa que desborda del mero cumplimiento formal de un conjunto predeterminado, más o menos amplio, de deberes y obligaciones empresariales y, más aún, la simple corrección a posteriori de situaciones de riesgo ya manifestadas. La planificación de la prevención desde el momento mismo del diseño del proyecto empresarial, la evaluación inicial de los riesgos inherentes al trabajo y su actualización periódica a medida que se alteren las circunstancias, la ordenación de un conjunto coherente y globalizador de medidas de acción preventiva adecuadas a la naturaleza de los riesgos detectados y el control de la efectividad de dichas medidas constituyen los elementos básicos del nuevo enfoque en la prevención de riesgos laborales que la Ley plantea".
} 
El deber de protección y, consecuentemente, las políticas de prevención no deben interpretarse como un conjunto de actuaciones técnicas, aisladas y externas a la empresa, sino como un conjunto organizado de acciones integradas en la gestión empresarial, y que, en todo caso, condicionan el poder de dirección y organización del empresario. En este sentido, cualquier decisión que se adopte en el seno empresarial, o cualquier acción que se ejecute, deberá tener en cuenta las consecuencias que de ella puedan derivarse para la seguridad y salud de los trabajadores. Las políticas de prevención de riesgos, en el ámbito laboral, gozan de fundamento jurídico suficiente para delimitar el poder directivo del empresario (expresión del derecho de libertad de empresa del artículo $38 \mathrm{CE}$ ). Cuando el artículo 14 LPRL reconoce el derecho del trabajador a la salud y seguridad, lo que, en realidad, pretende es la protección de un derecho de superior categoría, reconocido como fundamental en el artículo $15 \mathrm{CE}$ (el derecho del trabajador a la vida e integridad física y moral). El sustento o la base de toda política de prevención se concreta en la necesaria protección que debe otorgarse a este último precepto. Siendo así, contraponiendo los derechos enfrentados (derecho a la libertad de empresa y derecho a la vida), dada la importancia de los bienes protegidos por cada uno de los mismos y su diferente protección en el texto constitucional, no parece admisible que las facultades del empleador, aun derivadas del propio contrato laboral, puedan limitar o delimitar un derecho fundamental del trabajador. A este respecto, la doctrina constitucional declaró que, pese a que la propia naturaleza de la relación laboral exija la subordinación del trabajador a los poderes empresariales, no basta con la sola afirmación del interés empresarial para restringir los derechos fundamentales de aquel, dada la posición prevalente de estos en el ordenamiento jurídico ${ }^{17}$. Así, la seguridad e higiene (artículo 40.2 CE, en relación con el artículo 14 LPRL) derivadas del derecho fundamental a la vida e integridad personal (artículo 15 $\mathrm{CE}$ ), se convierten en instrumentos limitadores del poder de dirección del empresario y de su facultad de imposición de decisiones unilaterales (artículo $38 \mathrm{CE}$ ), abriéndose la puerta de su posible subordinación al respeto y la promoción de los intereses vitales del trabajador $^{18}$.

En conclusión, el deber de protección del empresario, en un contexto como el actual, tecnológicamente avanzado, se convierte en una obligación de gestión de los medios técnicos y organizativos a través de los cuales, de manera integrada en la actividad empresarial, el empleador debe eliminar, o cuanto menos reducir, los peligros creados con o por ocasión de la prestación asalariada. En esta línea, el derecho del trabajador

\footnotetext{
${ }^{17}$ Ver, RODRÍGUEZ CRESPO, María José, "La necesaria observancia de los derechos fundamentales en las relaciones laborales como límite inexcusable del poder de dirección empresarial", IUSLabor, núm. 2, 2018, pp. 173-185.

${ }^{18}$ GONZÁlEZ ORTEGA, Santiago, op. cit., p. 201. IGARTUA MIRÓ, María Teresa, "Sistema de prevención de riesgos laborales", Madrid, Editorial Tecnos, 2011, p.126-127.
} 
recogido en el artículo 14 LPRL, siendo la expresión y concreción del artículo 15 CE, se entenderá completamente amparado y respetado cuando el empresario adopte todas las medidas que, en función de la evolución de la técnica y de la ciencia, sean consideradas como las más adecuadas para la protección eficaz frente a posibles peligros. Con este objetivo, se hace necesaria la adopción y configuración de un plan empresarial de prevención de riesgos, a través del cual se lleven a cabo actuaciones tendentes a la identificación y evaluación de los peligros presentes en el trabajo, estableciendo y planificando, en función del resultado de la valoración efectuada, todas las medidas preventivas que los eliminen o, si no es posible, los controlen, minimizando sus efectos en caso de materialización. Sobre este particular, el artículo 16 LPRL integra, en el seno del deber de protección del empresario, su obligación de implantación y aplicación, en el ámbito empresarial, de un plan de prevención cuyos instrumentos esenciales, que podrán ser llevados a cabo por fases de manera programada, son la evaluación de los riesgos laborales y la planificación preventiva. Así, una vez valorado el nivel de riesgo al que se exponen los trabajadores, en la realización de sus responsabilidades profesionales, se adoptarán y organizarán todas las medidas, tecnológica y organizativamente factibles, para eliminar o reducir el peligro global existente.

Dentro de la actividad protectora, la evaluación de riesgos puede entenderse como el procedimiento dirigido a calcular la magnitud de los peligros creados en el seno de la prestación laboral, permitiendo a la empresa, a partir de su existencia, efectuar una adecuada elección de medidas protectoras. Se trata del punto de partida, a través del cual el empresario organizará y planificará el resto de las obligaciones implícitas en el deber de protección del artículo 14 LPRL (como las de proporcionar equipos de trabajo acordes al peligro al que el trabajador se expone, de formar al empleado respecto de los riesgos existentes o, en fin, de vigilar periódicamente su salud). Una valoración de riesgos que, en todo caso, por imperativo legal, "será actualizada cuando cambien las condiciones de trabajo"19. Trasladando el sentido de esta obligación al contexto en el que nos encontramos, en el que la necesaria recuperación económica (con la consecuente vuelta al trabajo) colisiona con la posibilidad de contagio, la evaluación del riesgo al que se expone cada trabajador se hace vital. Durante los períodos de control y contención del COVID-19, dado que los trabajadores permanecen desempeñando sus prestaciones asalariadas, todo empresario, en cumplimiento de este deber de protección, deberá efectuar una nueva evaluación de riesgos, que tenga en cuenta la existencia de este nuevo agente biológico, adoptando medidas adecuadas en función de la exposición en la que se encuentra cada uno de sus trabajadores. Solo de esta forma se podrán adaptar las políticas preventivas ya existentes (con anterioridad a la pandemia) al nuevo peligro generado por el referido virus, logrando una protección eficaz de la salud.

${ }^{19}$ Artículo 16.2.a LPRL. 


\section{La necesaria adaptación de las políticas preventivas a los riesgos generados por el COVID-19}

El desarrollo y la propagación del COVID-19 ha causado una situación de conmoción e inseguridad jurídica, colocando a empresarios y trabajadores en situaciones insólitas en cuanto a derechos enfrentados. Si bien es posible exigir la vuelta al trabajo, esta debe efectuarse con garantías y asegurando la protección de la salud del trabajador y, consecuentemente, su vida e integridad física y moral. Con este fin, y en cumplimiento del deber del artículo 14 LPRL, el empresario debe reiniciar su actividad empresarial partiendo de la necesaria actualización del plan de previsión de riesgos existente en el ámbito laboral. El SARS-Cov-2 se ha convertido, a estos efectos, en un nuevo agente biológico a evaluar y valorar en función del sector y del puesto, para poder definir el grado de exposición del trabajador y las medidas preventivas más eficaces.

El Real Decreto 664/1997, de 12 de mayo, sobre la protección de los trabajadores contra los riesgos relacionados con la exposición a agentes biológicos durante el trabajo (en adelante, RD 664/1997), define estos como “microorganismos (...) susceptibles de originar cualquier tipo de infección, alergia o toxicidad", estableciendo la obligación del empresario de determinar "la índole, el grado y la duración de la exposición de los trabajadores, para evaluar los riesgos que corren su seguridad y salud y determinar las medidas que proceda adoptar" ${ }^{20}$. En el momento de imposición del deber de evaluación, dicho Real Decreto viene a distinguir cuatro grupos distintos de agentes biológicos, en función del riesgo de infección que generan, atendiendo a su posibilidad de expansión y de la existencia, o no, de tratamiento o profilaxis $^{21}$. De conformidad con el criterio

\footnotetext{
${ }^{20}$ Artículo 3.2.a) Directiva 2000/54/CE, del Parlamento Europeo y del Consejo, de 18 de septiembre de 2000 , sobre la protección de los trabajadores contra los riesgos relacionados con la exposición a agentes biológicos durante el trabajo (en adelante, Directiva 2000/54/CE), en concordancia con lo establecido en el artículo 4 RD 664/1997 y artículos 16.2.a) LPRL.

${ }^{21} \mathrm{El}$ artículo $3 \mathrm{RD}$ 664/1997 establece que "los agentes biológicos se clasifican, en función del riesgo de infección, en cuatro grupos: a) agente biológico del grupo uno: aquel que resulta poco probable que cause una enfermedad en el hombre, b) agente biológico de grupo dos: aquel que pueda causar una enfermedad en el hombre y pueda suponer un peligro para los trabajadores, siendo poco probable que se propague a la colectividad y existiendo generalmente profilaxis o tratamiento eficaz, c) agente biológico del grupo tres: aquel que pueda causar una enfermedad grave en el hombre y presenta un serio peligro para los trabajadores, con riesgo de que se propague a la colectividad y existiendo, generalmente, una profilaxis o tratamiento eficaz; y d) agente biológico del grupo cuatro: aquel que, causando una enfermedad grave en el hombre, supone un serio peligro para los trabajadores, con muchas posibilidades de que se propague a la colectividad y sin que exista, generalmente, una profilaxis o un tratamiento eficaz".
} 
europeo, el SARS- Cov-2 es catalogado como de riesgo tres ${ }^{22}$, lo que significa que se trata de un agente de fácil desarrollo y contagio, pero que, en todo caso, existe un procedimiento de prevención y un medicamento. Quizá se deba advertir, como reflexión y crítica, que tal clasificación, atendiendo a la situación real y actual, no es del todo correcta, dado que, por el momento, no existe, aún, un tratamiento eficaz que lo neutralice. Así las cosas, la catalogación idónea de dicho agente sería, más bien, de tipo cuatro, es decir, de fácil desarrollo y expansión, sin que, por el momento, exista una profilaxis o medicamento totalmente efectivo. De esta forma, se estaría encasillando el SARS-Cov-2 en el grupo más peligroso de agentes biológicos. Dicha clasificación no es baladí ni nimia en el ejercicio del deber de protección del empresario, pues de ella va a depender tanto la evaluación del riesgo como las medidas preventivas a adoptar, dado que, a mayor grado de propagación e inexistencia de cura, más peligro deriva para el trabajador $^{23}$.

El deber empresarial de evaluación debe materializarse en el mismo momento de la puesta en marcha del proyecto empresarial, teniendo en cuenta, con carácter general, la actividad de la empresa y la exposición de los trabajadores a los riesgos que, posiblemente, se generen en el desarrollo de su prestación asalariada [artículo 16.2.a) LPRL] ${ }^{24}$. Se trata, por tanto, de un deber inicial que limita, desde sus propios principios, el poder de decisión del empresario (ya sea a nivel económico, organizativo, técnico o productivo). Una obligación que pervive durante la vigencia de la relación laboral y que, necesariamente, debe adaptarse a los cambios experimentados en las condiciones laborales. A estos efectos, el artículo 6.1 del Real Decreto 39/1997, de 17 de enero, por el que se aprueba el Reglamento de los servicios de prevención (en adelante, RSP), establece que, "en todo

\footnotetext{
${ }^{22}$ Ello de acuerdo a la clasificación efectuada en la Directiva 2019/1833, de la Comisión, de 24 de octubre de 2019, por la que se modifican los anexos I, III, V y VI de la Directiva 2000/54/CE, del Parlamento Europeo y del Consejo, con adaptaciones de carácter estrictamente técnico.

${ }^{23}$ El artículo 3.3 Directiva 2000/54/CE establece que la evaluación se efectuará teniendo en cuenta "la clasificación de los agentes biológicos que puedan constituir un peligro para la salud humana, a que se refiere el artículos 18, las recomendaciones de una autoridad responsable que indiquen que conviene controlar el agente biológico a fin de proteger la salud de los trabajadores cuando los trabajadores estén o puedan estar expuestos a dicho agente en razón de su trabajo, la información sobre las enfermedades que pudieran contraer los trabajadores en razón de la naturaleza de su trabajo, los efectos alergénicos o tóxicos potenciales vinculados a la índole del trabajo y el conocimiento de una enfermedad que se haya detectado en un trabajador y que esté directamente ligada a su trabajo".

${ }^{24}$ Ver comentario práctico: "Deber general de prevención y protección". Disponible en el siguiente enlace:https://insignis.aranzadidigital.es/maf/app/document?redirect=true\&srguid=i0ad6adc60000017289 $\underline{\text { 54a1e 0d13678b0\&marginal=DOCl2003\129\&docguid=If7b12010759c11dbbbc5010000000000\&ds }=A R}$ $\underline{Z}$ _LEGIS_CS\&infotype $=$ arz doctrina $; \&$ spos $=1 \&$ epos $=1 \& \mathrm{td}=0$ \&predefinedRelationshipsType $=$ documen tRetrieval $\&$ fromTemplate $=\&$ suggestScreen $=\& \&$ selectedNodeName $=\&$ selec $\_$mod $=$false $\&$ displayName $=$ \#
} 
caso, se deberá revisar la evaluación correspondiente a aquellos puestos de trabajo afectados cuando se hayan detectado daños en la salud de los trabajadores", teniendo en cuenta "el análisis de la situación epidemiológica, según los datos aportados por el sistema de información sanitaria y otras fuentes disponibles". El SARS-Cov-2 se ha convertido en un agente biológico de carácter epidemiológico, que afecta a las condiciones laborales de los trabajadores (riesgo de contagio e infección) y al que, necesariamente, debe hacer frente el empresario mediante un adecuado y adaptado plan de prevención de riesgos, en el que resultará indispensable una evaluación actualizada que tenga en cuenta, siempre, la presencia del virus en el ambiente de trabajo.

La actualización de la evaluación del riesgo se convierte en el instrumento fundamental de la prevención, a partir del cual se adoptarán las medidas profilácticas más eficaces. Se trata del punto de partida de cualquier política precautoria eficiente, pues, solo a partir de la valoración de la influencia de este agente biológico en cada uno de los puestos de trabajo, se conseguirá una protección global y completa del trabajador. La requerida actualización de la valoración del riesgo, presente en el ámbito del trabajo, implica una estimación detallada del peligro, en el sentido de que deberá atender al sector, a la empresa y a cada uno de los empleados. No es suficiente con establecer una evaluación global dentro del ámbito empresarial, sino que la misma debe entrar a valorar cada puesto de trabajo, pues no todos los trabajadores se encuentran expuestos al mismo riesgo (personal de oficina frente a personal de atención al público, por ejemplo). Así, a través de esta evaluación pormenorizada del grado de peligro, se conseguirá una evaluación actualizada que parta de la presencia del virus en el concreto quehacer de cada trabajador, que se encuentra desarrollando su prestación asalariada. En esta línea, dentro de un mismo ámbito empresarial, existirán puestos con distintos niveles de riesgo, respecto de los cuales, se adoptarán medidas adaptadas a estos.

Cualquier toma de decisión sobre las medidas preventivas a adoptar en cada empresa deberá basarse en la información recabada mediante la evaluación del riesgo de exposición específica. La actualización de la valoración del peligro existente en cada puesto de trabajo es un deber preliminar que, en todo caso, es de obligado cumplimiento. El establecimiento de medidas precautorias contra el COVID-19 sin una previa actualización de la evaluación conducirá a una política preventiva ineficaz e inadaptada, susceptible de quebrantamiento ante situaciones que se escapen de las disposiciones precautorias establecidas con carácter general. En términos similares, la adopción de las medidas preventivas establecidas ${ }^{25}$ y aconsejadas por los distintos organismos públicos

\footnotetext{
${ }^{25}$ Ver, artículo 7 del Real Decreto-ley 21/2020, de 9 de junio de 2020, de medidas de prevención, contención y coordinación para hacer frente a la crisis sanitaria ocasionada por el COVID-19.
} 
(ya sean nacionales, ya internacionales) ${ }^{26}$, sin una previa valoración del riesgo, conduce a un resultado poco aconsejable; pues solo a través de la valoración inicial del peligro y de la adaptación de la medida general a las concretas circunstancias del puesto de trabajo, se conseguirá una política precautoria eficaz. Las medidas aconsejadas por las distintas administraciones e instituciones públicas se convierten, así, en una máxima que debe guiar el plan de prevención de la empresa, acomodando este aquellas medidas a las particularidades de cada puesto de trabajo.

Esa evaluación inicial (de la situación de cada puesto de trabajo a la posible infección o contagio por el SARS-Cov-2) requiere de una constante adaptación al desarrollo y propagación de dicho virus, en el ámbito laboral. En otras palabras, el deber de protección del empresario no se agota con la primera valoración atinente a la presencia del COVID19 en el centro de trabajo, sino que la misma debe actualizarse en función del cambio de circunstancias. En este sentido, "esta evaluación deberá repetirse periódicamente y, en cualquier caso, cada vez que se produzca un cambio en las condiciones que pueda afectar a la exposición de los trabajadores a agentes biológicos" (artículo 4 RD 664/1997) ${ }^{27}$. Así, un posible contagio de un trabajador es, por sí, un hecho de relevancia para que el empresario vuelva a adaptar la evaluación inicial (ya actualizada a la presencia del virus en el lugar de trabajo) a la nueva situación surgida, en aras a analizar la efectividad del plan de prevención establecido, el posible defecto de este y los efectos potenciales que puedan derivarse de tal suceso, ajustando la política preventiva en todas sus medidas. Ante tal hipótesis, la Directiva 2000/54/CE establece que, "si un trabajador sufriere una infección y/o enfermedad que se sospeche sea consecuencia de una exposición, el médico o la autoridad responsable de la vigilancia sanitaria ofrecerá dicha vigilancia a otros trabajadores que hayan sufrido una exposición análoga", debiendo proceder "a una nueva evaluación del riesgo de exposición" (artículo 14.3). En definitiva, el empresario

\footnotetext{
${ }^{26}$ Ver, OIT: "In the face of a pandemic: ensure safety and health at work" y "Prevención y mitigación del COVID-19 en el trabajo. Lista de Comprobación", informes en los que se establecen las medidas preventivas generales a adoptar en el ámbito del trabajo. En el mismo sentido, se puede consultar, Subdirección General de Sanidad Ambiental y Salud Laboral. Dirección General de la Salud Pública, Calidad e Innovación: "Procedimientos de actuación para los servicios de prevención de riesgos laborales frente a la exposición al SARS-Cov-2, de 7 de octubre de 2020", en el que, tras diferenciar tres niveles de exposición al riesgo, establece medidas preventivas de organización del trabajo y de protección personal. En la misma línea, Ministerio de Trabajo y Economía Social: "Guía para la actuación en el ámbito laboral en relación al nuevo Coronavirus" y "Criterio operativo no 102/2020, sobre medidas y actuaciones de la Inspección de Trabajo y Seguridad Social relativas a situaciones derivadas del nuevo Coronavirus (SARSCov-2)". De manera paralela,"Instituto de Seguridade e Saúde Laboral de Galicia (en adelante, ISSGA): "Guía básica ISSGA para la elaboración del plan de contingencias", o el Instituto Vasco de Seguridad y Salud Laborales (en lo siguiente, OSALAM): "Guía para la elaboración del plan de contingencia". Todos disponibles en formato digital.

${ }^{27}$ También véase el artículo 3.2.c) Directiva 2000/54/CE.
} 
deberá velar por que "se adapten estas medidas, a fin de tener en cuenta el cambio de las circunstancias y tender a la mejora de las situaciones existentes" (artículo 6 Directiva 89/391/CE).

El deber de actualizar la evaluación del riesgo, en concordancia con las modificaciones operadas en las condiciones laborales [artículo 16.2.a) LPRL], implica, necesariamente, la evolución continua del plan de prevención, en concordancia a los constantes cambios acaecidos en la organización del trabajo. De este modo, la obligación de protección, impuesta al empresario, se encuentra en constante desarrollo, sometiéndose tanto a la exigencia de adaptar la evaluación inicial del riesgo a los nuevos peligros acaecidos como a la necesidad de aplicar las novedosas medidas preventivas derivadas del progreso científico, técnico o tecnológico. El concepto de salud laboral evoluciona con el paso del tiempo, comprendiendo en su ámbito nuevas realidades que, en épocas pasadas, eran del todo inimaginables. Como se aprecia, el progreso del "bienestar en el trabajo" implica la necesaria evolución de las políticas preventivas, que, necesariamente, deberán actualizarse para acomodarse a las nuevas enfermedades y contingencias surgidas con o por ocasión de la prestación asalariada. El COVID-19 ha supuesto la necesidad de adaptar el concepto de "salud laboral" a la existencia de un nuevo agente biológico que pone en serio peligro la vida del trabajador.

Un caso particular, de vital protección, es aquel del trabajador cuya salud es muy sensible a la presencia del COVID-19, mereciendo un especial trato preventivo y tuitivo. En tales supuestos, cabe recordar el deber que se impone al empresario de garantizar, "de manera específica, la protección de los trabajadores que, por sus propias características personales o estado biológico conocido, incluidos aquellos que tengan reconocida la situación de discapacidad física, psíquica o sensorial, sean especialmente sensibles a los riesgos derivados del trabajo", debiendo, a tal fin, "tener en cuenta dichos aspectos en la evaluación de los riesgos y, en función de esta, adoptar las medidas preventivas y de protección necesarias" (artículo 25 LPRL) ${ }^{28}$. Con el fin de ser precisos, el SARS-Cov-2 genera situaciones de particular protección respecto a trabajadores que presentan patologías cardiovasculares, hipertensión arterial, diabetes, enfermedad pulmonar crónica, inmunodeficiencias, procesos oncológicos en tratamiento activo, embarazo o mayores de sesenta años. A estos efectos, el Ministerio de Sanidad ${ }^{29}$ señala que serán los

\footnotetext{
${ }^{28}$ En el mismo sentido, se pronuncia el artículo 14.3 Directiva 2000/54/CE, al establecer que "la evaluación a que se refiere el artículo 3 debería identificar a los trabajadores a los que pueda ser necesario aplicar las medidas de especial protección".

${ }^{29}$ Instituto Nacional de la Seguridad Social: "Actualización a 15 de abril de 2020, de las instrucciones aclaratorias al nuevo procedimiento de remisión de partes de los servicios públicos de salud por el coronavirus", disponible en el siguiente enlace:

https://www.semg.es/images/2020/Coronavirus/20200415_instrucciones_partes_coronavirus.pdf
} 
servicios de prevención de riesgos laborales de cada empresa los encargados de calificar a estos trabajadores como 'especialmente susceptibles', debiendo establecer la naturaleza de la singular sensibilidad, teniendo en cuenta la existencia o no de condiciones que permitan a estas personas efectuar su trabajo sin elevar el riesgo para sí mismos.

\section{La necesaria protección del trabajador en régimen de teletrabajo}

Una vez actualizada la valoración del riesgo, en función de sus resultados, el empresario habrá de adoptar las medidas que, siendo acordes a la evolución técnica y científica, prevengan y protejan al trabajador del peligro de contagio e infección. No se olvide que el legislador prevé que, "si los resultados de la evaluación a la que se refiere el artículo 4 pusieran de manifiesto un riesgo para la seguridad y la salud de los trabajadores por exposición a agentes biológicos, deberá evitarse dicha exposición" (artículo 6 RD 664/1997). En este sentido, la primera medida a adoptar, y siendo ella la más efectiva, es la elusión del riesgo mediante sistemas alternativos de desarrollo de la prestación asalariada. O, lo que es lo mismo, de ser posible y factible, se priorizarán sistemas alternativos de prestación de servicios que eviten la presencia del trabajador en el centro de trabajo.

El trabajado a distancia, y, en especial, el teletrabajo ${ }^{30}$, se ha convertido en la primera medida de protección por excelencia, teniendo, esta figura una oportunidad única e histórica para demostrar sus beneficios ${ }^{31}$. La necesaria continuidad de la actividad productiva y la recuperación de múltiples sectores y empresas, en un contexto como el actual, con posibilidades de nuevos contagios y rebrotes, colisiona en parte, con el derecho a la protección de la salud de toda persona. Sin embargo, un sistema equilibrado, en el que se pondere el derecho a la vida del trabajador (y, por tanto, el derecho a la

\footnotetext{
${ }^{30}$ El término teletrabajo hace referencia a una modalidad de trabajo a distancia en la que los medios a utilizar se concretan en equipos informáticos, de telecomunicaciones y análogos. Ver, en cuanto a la definición del término y a sus modalidades, MELLA MÉNDEZ, Lourdes, "Sobre una nueva manera de trabajar: el teletrabajo", Revista Doctrinal Aranzadi, vol. V, 1998, pp. 1-27 (BIB:1998/639); LOUSADA AROCHENA, Francisco y RON LATAS, Ricardo Pedro, "Una mirada periférica al teletrabajo, en el trabajo a domicilio y el trabajo a distancia en el derecho español", en VV.AA. MELLA MÉNDEZ, Lourdes, y VILLALBA SÁNCHEZ, Alicia, Trabajo a distancia y teletrabajo. Estudios sobre su régimen jurídico en el derecho español y comparado, Pamplona, Aranzadi, 2015, pp. 31- 45; THIBAULT ARANDA, Javier: "Definición y Tipología", El teletrabajo. Análisis jurídico-laboral, Madrid, Consejo Económico Social, 2001, pp. 23-38.

${ }^{31}$ El artículo 5 RD 8/2020 establece el carácter preferente del trabajo a distancia, disponiendo que, en particular, "se establecerán sistemas de organización que permitan mantener la actividad por mecanismos alternativos, particularmente por medio del trabajo a distancia, debiendo la empresa adoptar las medidas oportunas si ello es técnica y razonablemente posible y si el esfuerzo de adaptación necesario resulta proporcionado".
} 
protección de su integridad física y moral) y la necesaria reactivación económica, es aquel en el que la prestación asalariada se desarrolle en un lugar distinto al centro de trabajo (preferentemente en el domicilio del trabajador), evitando así, en este espacio, la acumulación de personal y, consecuentemente, la posibilidad de nuevos $\operatorname{contagios}^{32}$. El aislamiento social ha resultado ser una medida efectiva en aras a la contención del COVID-19; una medida que, incluso, en la fase actual (de recuperación y restablecimiento de la normalidad) debe seguir vigente, pues contribuye a evitar la expansión de la pandemia sufrida. Y a esta finalidad responde el trabajo a distancia, dado que el teletrabajador, sin tener que desplazarse diariamente y sin sufrir riesgo de contagio e infección, desarrolla su prestación asalariada y contribuye a la reactivación de la economía.

La proliferación del régimen del trabajo a distancia, en estos tiempos de pandemia, ha provocado la necesidad de otorgarle, a este, una cobertura legal y un régimen jurídico desarrollado y suficiente, y a cuyo fin responde el reciente Real Decreto-Ley 28/2020, de 22 de septiembre, de trabajo a distancia (en lo siguiente, RD 28/2020). Una normativa que, si bien se puede considerar como fruto de la situación de emergencia provocada por el COVID-19, sin embargo, no regula los supuestos de teletrabajo provocados por la crisis sanitaria, quedando estos al margen de esta normativa. En este sentido, la disposición transitoria tercera establece que "al trabajo a distancia implantado excepcionalmente en aplicación del artículo 5 del Real Decreto-ley 8/2020, de 17 de marzo, o como consecuencia de las medidas de contención sanitaria derivadas de la COVID-19, y mientras estas se mantengan, le seguirá resultando de aplicación la normativa laboral ordinaria", es decir, el antiguo artículo 13 del del Real Decreto Legislativo 2/2015, de 23 de octubre, por el que se aprueba el texto refundido de la Ley del Estatuto de los Trabajadores (en adelante, ET).

Fuera de las críticas que merece esta remisión a "la normativa laboral ordinaria" 33 , en materia de prevención laboral, ni la regulación ordinaria (entendemos, por esta, LPRL) ni

\footnotetext{
${ }^{32}$ En experiencias anteriores de enfermedades víricas, ya se recurrió al teletrabajo como solución perfecta para la continuidad de la actividad económica, con el consiguiente mantenimiento del empleo, dado que, con este modo de trabajar, los trabajadores pudieron seguir prestando servicios en condiciones de un cierto aislamiento seguro, sin exponerse a los riesgos de contagio e infección. Así, el Ministerio de Sanidad y Política Social presentó, en julio de 2009, una guía para la elaboración del plan de actuación de las empresas o centros de trabajo frente a emergencias derivadas del virus $\mathrm{H} 1 \mathrm{~N} 1$, en la que se abogada por el teletrabajo como medida de referencia.

${ }^{33}$ La remisión a la "normativa ordinaria" se dirige, necesariamente, al ET, concretamente al artículo específico que regula el trabajo a distancia (artículo 13 ET). Precepto que, en su tenor literal, dispone que "las personas trabajadoras podrán prestar trabajo a distancia en los términos previstos en el Real Decretoley 28/2020, de 22 de septiembre, de trabajo a distancia". De esta forma, se ha creado una remisión sin sentido, en la que, siguiendo la línea legal (de la disposición transitoria tercera del RD 28/2020, al artículo
} 
la actual (artículo 15 y 16 RD 28/2020), se adaptan a la nueva realidad laboral, cada vez más tecnológica y descentralizada. Si bien dicho real decreto tuvo la oportunidad de profundizar y desarrollar un derecho a la salud laboral del trabajador a distancia que se acomodara a las exigencias de la "Cuarta Revolución Industrial", lo cierto es que, este se ha quedado en aspectos puramente formales, realizando una remisión general a la LPRL (artículo 15 RD 28/2020) y declarando, en su artículo 16 RD 28/2020, la mera existencia de especialidades típicas del trabajo a distancia, pero sin entrar en detalle en cuanto a su formulación. Siendo así, en materia preventiva, la exclusión del trabajador a distancia derivado del COVID-19, en cuanto a la aplicación de esta regulación, no genera efecto alguno (ni positivo ni negativo), pues la nueva normativa, al igual que la "normativa laboral ordinaria", se remiten a la clásica LPRL.

Tanto el trabajador a distancia derivado de la crisis sanitaria como el nuevo trabajador del RD 28/2020 se regirán, en materia preventiva, por la LPRL, si bien, para este último supuesto, se prevén una serie de matizaciones (sin eficacia práctica) en el artículo 16 del nuevo real decreto. En todo caso, se repite el esquema tradicional por el que se distribuyen las responsabilidades, de tal forma que el empresario sigue a ser el titular del deber de protección (artículo 14 LPRL). Así, este será el encargado y responsable de elaborar un plan de prevención en el que se integre una adecuada previsión respecto al teletrabajo, procediendo a la evaluación de sus riesgos y a la adopción o adaptación de las medidas de protección. La valoración del riesgo, en empresas en las que sea factible el trabajo a distancia, debe tener presente esta opción, procediendo a evaluar los riesgos, ahora derivados de esta forma de desarrollo de la prestación asalariada (no del posible contagio en el centro de trabajo).

Ahora bien, tanto a la hora de evaluar como en el momento de la aplicación práctica de las medidas preventivas y de protección, el teletrabajador asumirá una responsabilidad mayor que en el caso ordinario del trabajo presencial. A estos efectos, los artículos 5.1.b) y 29 LPRL imponen al trabajador la obligación de "velar, según sus posibilidades y mediante el cumplimiento de las medidas de prevención que, en cada caso, sean adoptadas, por su seguridad y salud en el trabajo y por la de aquellas otras personas a las que pueda afectar su actividad" ${ }^{34}$. De esta forma, se establece un deber de colaboración del trabajador, que siempre es accesorio al deber de protección del empresario $^{35}$, pero que, en el régimen del teletrabajo, se refuerza. El hecho de trabajar

13 ET y nuevamente al RD 28/2020), se vuelve a la normativa de partida. Una deficiencia del nuevo real decreto que está siendo debatida, e incluso criticada, por la doctrina, buscando esta una solución e intentando dar una interpretación a lo que se debe entender por "normativa laboral ordinaria".

${ }^{34}$ En el mismo sentido, el artículo 13 Directiva 89/391/CE.

${ }^{35}$ El citado artículo 14 LPRL impone al empresario el deber de protección, obligación que no se anula, ni se reduce, en el campo del teletrabajo. Véase, también, el artículo 8 del Acuerdo Marco Europeo sobre 
fuera del centro de trabajo, pudiendo el trabajador elegir su lugar de prestación de servicios (en la mayoría de los casos, coincidente con su domicilio particular), conlleva a su mayor responsabilidad en materia preventiva, dada la limitación de poderes que el empresario puede ejercer sobre dicho espacio. En otras palabras, "la carga obligacional del trabajador se endurece y equipara a la del propio empresario, alejándose del carácter secundario que aquel asume en el supuesto general y convirtiéndolo en un colaborador necesario en la aplicación práctica y gestión diaria de los múltiples aspectos que la prevención exige en el día a día"36.

Como se indicó en el apartado tercero, el plan de prevención empresarial debe partir de una detallada evaluación de los riesgos laborales, que, en este ámbito, tenga en cuenta la existencia del trabajo a distancia y las circunstancias de los trabajadores que lo desarrollan, con la finalidad de garantizar su seguridad y salud laboral ${ }^{37}$. Así, el empresario, en ejecución de su deber de valorar los posibles peligros, deberá tomar en cuenta cuatro variables fundamentales: el lugar de prestación del trabajo (que, en la mayoría de los supuestos, en el contexto del COVID-19, coincide con su domicilio familiar), los instrumentos de trabajo utilizados, el sistema de comunicación entre la empresa y el trabajador, y las características personales y profesionales de este último $^{38}$.En este sentido, el artículo 8.3 del Acuerdo Marco Europeo sobre Teletrabajo (AMET) dispone que, "para verificar la correcta aplicación de las normas en materia de salud y seguridad, el empresario, los representantes de los trabajadores y/o las autoridades competentes tienen acceso al lugar del teletrabajo dentro de los límites de

Teletrabajo (en lo siguiente, AMET), "el empresario es responsable de la protección de la salud y de la seguridad profesionales del teletrabajador conforme a la Directiva 89/391, así como a las directivas particulares, nacionales y convenios colectivos pertinentes".

${ }^{36}$ MELLA MÉNDEZ, Lourdes.: "Configuración general del trabajo a distancia en el derecho español”, en VV.AA. MELLA MÉNDEZ, Lourdes. (directora), SIERRA BENÍTEZ ESPERANZA MACARENA, CARDONA RUBET, María Belén, y CABEZA PEREIRA, Jaime, El teletrabajo en España: aspectos teóricos-prácticos de interés, Madrid, La Ley Wolters Kluwer, 2017, p. 68.

${ }^{37} \mathrm{El}$ artículo 16 RD 28/2020, en todo caso inaplicable al trabajador a distancia derivado de la crisis sanitaria, matiza (simplemente) este extremo, al establecer que "la evaluación de riesgos y la planificación de la actividad preventiva del trabajo a distancia deberán tener en cuenta los riesgos característicos de esta modalidad de trabajo, poniendo especial atención en los factores psicosociales, ergonómicos y organizativos. En particular, deberá tenerse en cuenta la distribución de la jornada, los tiempos de disponibilidad y la garantía de los descansos y desconexiones durante la jornada". Se abre la puerta, en esta nueva regulación, a la adaptación de la LPRL a las peculiaridades del trabajo a distancia, pero sin llegar a desarrollar ni profundizar en estos concretos extremos; convirtiéndose la norma en una simple declaración de intenciones sin efectividad práctica.

38 Ver, MELLA MÉNDEZ, Lourdes, "La seguridad y salud en el teletrabajo", en. VV.AA. MELLA MÉNDEZ (editora), Lourdes, y VILLALBA SÁNCHEZ, Alicia (coordinadora), Trabajo a distancia y teletrabajo. Estudios sobre su régimen jurídico en el derecho español y comparado, Pamplona, Aranzadi, 2015, pp. 178-204 
la legislación y de los convenios nacionales"39. De ahí, la necesaria colaboración del trabajador en esta materia que, en atención a su derecho a la intimidad personal y familiar (reconocido como derecho fundamental, en el artículo $18 \mathrm{CE}$ ), deberá ofrecer su consentimiento para la inspección y valoración del lugar de trabajo por un tercero ajeno a su ámbito más íntimo. El hecho de destinar un mismo espacio para el desarrollo de la vida personal, familiar y profesional exige la aceptación de ciertas restricciones en un doble sentido, dado que, por un lado, se reduce el poder empresarial y, por el otro, se limita el derecho de intimidad del trabajador.

Sin embargo, a este respecto, el artículo 5 RD 8/2020 establece que, "con el objetivo de facilitar el ejercicio de la modalidad de trabajo a distancia en aquellos sectores, empresas o puestos de trabajo en los que no estuviera prevista hasta el momento, se entenderá cumplida la obligación de efectuar la evaluación de riesgos (...), con carácter excepcional, a través de la autoevaluación realizada voluntariamente por la propia persona trabajadora". En otros términos, en el contexto del COVID-19, y dada la necesidad de evitar los desplazamientos y el contacto social, se prevé que sea el trabajador el que autoevalúe los peligros a los que podría enfrentarse con o por ocasión de la prestación asalariada a distancia ${ }^{40}$. Así, prescindiendo de la necesidad de inspección por un tercero, será el trabajador el encargado de realizar la valoración de los riesgos que puedan generarse en el desempeño de sus funciones profesionales, desde su domicilio, al igual que la verificación de las medidas adoptadas. En este sentido, el deber de evaluación, en el teletrabajo se desplaza desde su titular por excelencia (el empresario) a la contraparte de la relación laboral (el trabajador). No obstante, se debe precisar que, en el ámbito del trabajo a distancia, la obligación de protección del empresario, en la que se engloba la necesaria valoración del peligro, no desaparece, pues aquel sigue siendo el titular de ese deber. Ahora bien, dadas las particulares condiciones vividas, se permite

\footnotetext{
${ }^{39}$ Cierto es que dicho precepto hace referencia a la necesidad del consentimiento en una fase posterior a la evaluación del peligro, dada su referencia a "verificar la correcta aplicación de las normas en materia de salud y seguridad". Sin embargo, una interpretación amplia de dicho precepto llevaría, de modo paralelo, a la misma exigencia en relación con el momento de valoración del riesgo; de tal forma que el consentimiento del trabajador será requerido ya en la fase previa de evaluación, y en cualquier otra visita posterior que se realice en aras a comprobar la adecuada aplicación de las medidas preventivas adoptadas. 40 "A pesar de bondad de la medida y de su necesaria aceptación como imprescindible en este contexto, no deja de echarse en falta algún elemento adicional de clarificación, que permita una mejor implementación de la autoevaluación (...). De un lado, hubiera sido deseable que, aunque fuera con carácter orientativo, se hubiese elaborado por parte del Ministerio de Trabajo un modelo de documento de autoevaluación a cumplimentar con sencillez por parte del trabajador (...). De otra parte, hubiera sido oportuno que la norma hubiese precisado el significado del carácter voluntario de la autoevaluación y, en particular, los efectos derivados de la negativa del trabajador a cumplimentar el documento de autoevaluación". CRUZ VILLALÓN, J.: "Teletrabajo y coronavirus: de la emergencia a la permanencia", Derecho de las Relaciones Laborales, núm. 4, 2020, p. 409.
} 
atribuir e, incluso, exigir al trabajador un papel más activo en materia de prevención, pues la distancia (medida fundamental de control y freno del virus), y el hecho de trabajar desde el domicilio particular, condiciona y restringe el poder de valoración y vigilancia del empresario.

La autoevaluación de riesgos laborales por el teletrabajador exigirá, en todo caso y siendo ello fundamental, la necesidad de proporcionarle, con carácter previo, la información y formación necesarias para la correcta valoración del peligro y el desarrollo seguro de su prestación asalariada. En esta línea, el artículo 18 LPRL dispone que "el empresario adoptará las medidas adecuadas para que los trabajadores reciban todas las informaciones necesarias" respecto a la actividad precautoria; mientras que el artículo 19 LPRL impone a aquel el "garantizar que cada trabajador reciba una formación teórica $y$ práctica, suficiente y adecuada en materia preventiva". En consecuencia, no es suficiente con que el empresario confíe en su empleado el deber de evaluación y verificación, pues dicha delegación exigirá la comprobación de que el teletrabajador se encuentra plenamente capacitado para desarrollar estas funciones precautorias, para lo cual serían necesarios los mencionados trámites de información y formación. Así, en el ámbito del teletrabajo, resulta importante que el empresario cumpla con su obligación legal de informar y formar a cada trabajador respecto de cada uno de los riesgos específicos que puedan afectar a su puesto de trabajo, pues, solo a través de esta vía, este se encontrará capacitado para realizar aquellas tareas que, de ordinario, en el trabajo presencial, corresponden a la parte empresarial.

El artículo 8.2 AMET exige al empresario que informe al "teletrabajador de la política de la empresa en materia de salud y seguridad en el trabajo, en especial sobre las exigencias relativas a las pantallas de datos". Respecto del último inciso del precepto, cabe advertir que dicha precisión resulta oportuna y lógica, dado que la forma común de teletrabajar es a través de las nuevas tecnologías (lo que implica la utilización de pantallas de visualización de datos). A estos efectos, el Real Decreto 488/1997, de 14 de abril, sobre disposiciones mínimas de seguridad y salud relativas al trabajo con equipos que incluyen pantallas de visualización (en lo siguiente, RD 448/1997) ${ }^{41}$, establece las medidas preventivas básicas a adoptar en situaciones de teletrabajo a través de dispositivos tecnológicos, pero que, en todo caso, deberán a adaptarse a los concretos riesgos identificados a través de la valoración inicial y a las condiciones del puesto. Ahora bien, resulta evidente que tal información deberá completarse con la relativa al resto de aspectos importantes en esta modalidad de trabajo, como pudiera ser la relacionada con

\footnotetext{
${ }^{41}$ Resultado de la transposición de la Directiva 90/207/CE, del Consejo, de 29 de mayo de 1999, referente a las disposiciones mínimas de seguridad y salud relativas al trabajo con equipos que incluyen pantallas de visualización.
} 
las posibles enfermedades o accidentes profesionales que amenazan la salud del teletrabajador. De este modo, "la información sobre la política de empresa en la materia exige una comunicación lo más amplia posible, que abarque todo el contenido del plan de prevención, o sea, tanto los posibles riesgos como las medidas adoptadas para evitarlos, individuales y colectivas, incluidas las de emergencia"42.

De manera complementaria a la exigencia de comunicación, el trabajador deberá ser formado sobre los riesgos y las medidas a adoptar en el desarrollo de su prestación asalariada a distancia. Si bien la exigencia de información y formación parten del mismo punto y se dirigen al mismo objetivo, la realidad de estas muestra un contenido diferente. Mientras que, en la primera de ellas, el trabajador aparece como simple receptor de una serie de informaciones que son transmitidas por el empresario, sin que le sea requerido ningún comportamiento de respuesta; la segunda de ellas -la formación- implica, de por sí, una conducta activa del teletrabajador, en el plano teórico y práctico. Este deberá asistir a cursos específicos, impartidos ya sea de manera presencial u on-line, en los que, de modo participativo y demostrando su asimilación de conceptos, se forme en la materia de prevención de riesgos laborales. Con todo, dicha formación deberá impartirse dentro de la jornada de trabajo y, de no ser posible, fuera de la misma, pero con descuento del tiempo invertido en ella.

La política preventiva en materia de teletrabajo implica, por tanto, una valoración y previsión específica, en la que se contemplen las particularidades de dicha forma de prestación asalariada, los concretos peligros a los que se enfrenta el teletrabajador, así como las enfermedades profesionales propias de esta manera de trabajar. Cabe atender tanto a los riesgos físicos, derivados de la interrelación del trabajador con el lugar o con el equipo de trabajo, como de riesgos psicosociales u organizacionales, surgidos de la interacción de la particular personalidad y capacidad profesional de aquel con las específicas características de este modo de prestar servicios. El trabajo a distancia otorga al teletrabajador una responsabilidad superior en cuanto a la forma de desarrollo y organización de la actividad laboral. Y es aquí, en esta "delegación" del poder organizativo y de control del empresario, donde se encuentra el mayor peligro al que aquel se enfrenta. En este ámbito, es habitual y común que el sujeto prolongue sus jornadas ordinarias, o esté pendiente de cualquier requerimiento laboral que pueda producirse a lo largo del día. Esta dependencia del trabajador al trabajo, facilitada por la digitalización de la relación laboral, genera nuevos riesgos a los que enfrentarse, causantes de enfermedades conocidas como "tecno-estrés", "tecno-depresión", "tecnoadicción" o "tecno-fatiga". De ahí, la necesidad de regular más detalladamente, en este

${ }^{42}$ MELLA MÉNDEZ, Lourdes, op. últ. cit., p. 200. 
ámbito, y como medida de protección de la salud laboral, el conocido derecho a la desconexión digital ${ }^{43}$.

\section{La adopción de medidas organizativas, higiénicas y de control en el centro de trabajo}

El artículo 6 RD 664/1997 establece que, de no ser posible evitar la exposición del trabajador al SARS-Cov-2 (mediante, como se señaló, el teletrabajo), "se reducirá el riesgo de exposición al nivel más bajo posible". Durante la jornada laboral, el trabajador, posible víctima de un contagio e infección, deberá estar protegido mediante una política precautoria eficaz, que, partiendo de la necesaria actualización de la evaluación del peligro, asegure su vida e integridad física y moral mediante el establecimiento de medidas de tipo higiénico y de vigilancia. En este sentido, la propia OIT reconoció que "no todas las empresas pueden sustituir los procesos de trabajo mediante formas remotas de prestación de servicios, de tal forma que, en estos casos, el siguiente paso es implementar controles de ingeniería"44, de organización e higiene.

La valoración del riesgo al que se expone el trabajador, derivado de la posible presencia de dicho agente biológico en el centro de trabajo, no solo es necesaria en una fase previa de evaluación preventiva, sino que aquella influirá en la medida a adoptar respecto de cada puesto de trabajo. Como se señaló, solo en función del riesgo valorado y determinado, se adoptará una política precautoria y de protección eficiente que, adaptándose a las condiciones laborales específicas de cada empleado, establezca mandatos preventivos claros, dirigidos a evitar el contagio mediante la adopción de acciones profilácticas y de control de la salud. En consecuencia, en función del nivel de riesgo al que se expone el trabajador, el "Procedimiento de actuación para los servicios de prevención de riesgos laborales frente a la exposición al SARS-COV-2”, elaborado por el Gobierno, establece (una vez identificadas las tres situaciones de peligro: exposición de riesgo, exposición de bajo riesgo y baja probabilidad de exposición), las distintas medidas a adoptar en cada uno de estos contextos ${ }^{45}$. Únicamente partiendo de este requerimiento inicial de evaluación, se logrará que las medidas adoptadas sean eficaces frente a la existencia del virus en el entorno laboral.

\footnotetext{
${ }^{43}$ Véase, TORRES GARCÍA, B.: "Sobre la regulación legal de la desconexión digital en España: valoración crítica", Revista internacional y comparada de relaciones laborales y derecho del empleo, vol. 8, núm. 1, 2020, pp. 239-262.

${ }^{44}$ OIT: "Safe and healthy return to work during COVID-19 pandemic", p. 7. Disponible en el siguiente enlace:https://www.ilo.org/wcmsp5/groups/public/---ed_protect/---protrav/--safework/documents/briefingnote/wcms 745549.pdf

45 Subdirección General de Sanidad Ambiental y Salud Laboral. Dirección General de la Salud Pública, Calidad e Innovación, op. cit.
} 
De nuevo, es el empresario el titular del deber de aplicar las medidas preventivas oportunas. De hecho, se establece que será el titular de la actividad económica el que deberá adoptar los mandatos necesarios para cumplir las medidas de higiene y prevención de los trabajadores, asegurando, en todo caso, que éstos "tengan permanentemente a su disposición, en el lugar de trabajo, geles hidroalcohólicos, o desinfectantes con actividad viricida autorizados y registrados por el Ministerio de Sanidad para la limpieza de manos, o, cuando esto no sea posible, agua y jabón". Asimismo, de no poder garantizar "la distancia de seguridad interpersonal de aproximadamente dos metros, se asegurará que los trabajadores dispongan de equipos de protección adecuados al nivel de riesgo" 46 . Se impone, por tanto, al empresario el deber de adoptar, ante la posible presencia del COVID-19 en su unidad productiva, medidas de tipo organizativo, profiláctico y de control que se adapten a las condiciones de trabajo de cada puesto.

Todo empresario deberá adoptar tres tipos de medidas, dirigidas todas ellas (aunque de distinta forma) a evitar el contacto físico entre trabajadores, proteger su cuerpo frente a cualquier foco de peligro $\mathrm{y}$, por tanto, orientadas a prevenir cualquier posible contagio e infección. En este sentido, se establecen, en primer lugar, medidas de tipo organizativo, a través de las cuales se procederá a la modificación de la disposición de los puestos, a la reorganización de los turnos y del resto de condiciones de trabajo existentes en los centros, para garantizar la posibilidad de mantener la distancia de seguridad interpersonal. También se deberán "realizar los ajustes en la organización horaria que resulten necesarios para evitar el riesgo de coincidencia masiva de personas, trabajadoras o no, en espacios o centros de trabajo" "47. El plan de prevención contra el SARS-Cov-2 deberá, así, establecer medidas que, de una u otra forma, garanticen la dispersión y el distanciamiento social, tanto entre los propios trabajadores como entre estos y el resto de personal ajeno a la empresa. El evitar el contacto físico, mediante medidas de este tipo, es uno de los fines a los que debe orientarse toda política preventiva, de tal forma que, estudiando el volumen de personas presentes en las instalaciones de la empresa en cada una de las franjas horarias, el empresario deberá reorganizar su plantilla y producción, en beneficio de la salud y seguridad de sus trabajadores.

En segundo lugar, a nivel higiénico, el artículo 8 Directiva 2000/54/CE impone al empresario la obligación de proveer a los trabajadores "de trajes de protección apropiados" o, lo que es lo mismo, de "cualquier equipo destinado a ser llevado o sujetado por el trabajador para que le proteja de uno o varios riesgos que puedan

\footnotetext{
46 Artículo 4.1 de la Orden SND/399/2020, de 9 de mayo, para la flexibilización de determinadas restricciones de ámbito nacional, establecidas tras la declaración del estado de alarma en aplicación de la fase 1 del Plan para la transición hacia la nueva normalidad (en adelante, Orden SND/399/2020).

${ }^{47}$ Artículos 5 Orden SND/399/2020.
} 
amenazar su seguridad o salud laboral" (artículo 4.8 LPRL). Así, en situaciones de exposición al riesgo, el empresario deberá proporcionar a aquel un equipo de protección individual (en adelante, EPI) adaptado al nivel de peligro y velar por su correcta utilización. A estos efectos, el artículo 3 Real Decreto 773/1997, de 30 de mayo, sobre disposiciones mínimas de seguridad y salud relativas a la utilización por los trabajadores de equipos de protección individual (en adelante, RD 773/1997), establece que el empresario estará obligado a determinar los puestos de trabajo en los que deba recurrirse a la protección individual y precisar, para cada uno de estos puestos, el riesgo o riesgos frente a los que debe ofrecerse protección, las partes del cuerpo a proteger y el tipo de equipo o equipos que deberán utilizarse. Como se adelantó, no todo trabajador está expuesto al mismo nivel de peligro, ya que su grado de exposición variará en función del sector, la empresa en cuestión y las tareas a desempeñar. Esa determinación del riesgo, llevada a cabo en la fase inicial de la elaboración del plan de contingencias, decidirá no solo sobre la necesidad o no de proporcionar EPIs, sino sobre el tipo de equipamiento que deba ofrecerse en aquellas situaciones en las que sí es requerida su utilización. Desde este punto de vista, mientras que los trabajadores calificados (por la valoración inicial) como de "baja probabilidad de exposición" no precisan de este tipo de material, aquellos otros calificados como "exposición de bajo riesgo" o de "exposición de riesgo" sí necesitan de componentes de EPI de protección biológica y, en ciertas circunstancias, de protección frente a aerosoles y salpicaduras ${ }^{48}$.

Para la elección de estos equipamientos de seguridad, el empresario, con carácter previo, tiene que "definir las características que deberán reunir dichos equipos de protección individual para garantizar su función, teniendo en cuenta la naturaleza y magnitud de los riesgos que deban proteger", siendo necesario, para ello, comparar las características de los existentes en el mercado (artículo 6 RD 773/1997). La necesidad de proveer al trabajador de un EPI requiere, en todo caso, la adaptación del mismo a las condiciones de su puesto de trabajo, para así conseguir una protección que, permitiendo el normal desempeño de sus responsabilidades profesionales, asegure, de manera efectiva, su vida y salud. La elección del equipamiento de protección resulta, por tanto, de vital importancia y dependerá, obviamente y siempre, de la valoración de la exposición al peligro al que se enfrenta el trabajador. A mayor tasa de riesgo (personal sanitario asistencial), más completo debe ser el equipo proporcionado (bata impermeable, mascarilla FPP2, FPP3, gafas de protección, pantallas, guantes y contenedores de grandes residuos, entre otros). Y, viceversa, a menor nivel de peligro (personal no sanitario, de limpieza, de ayuda a domicilio, etc.), la exigencia de un equipo de protección se reduce, llegando, incluso, a establecerse que, en el supuesto de "baja exposición al riesgo"

\footnotetext{
${ }^{48}$ Subdirección General de Sanidad Ambiental y Salud Laboral. Dirección General de la Salud Pública, Calidad e Innovación, op. cit.
} 
(personal administrativo sin atención directa al público, por ejemplo), no es necesaria la utilización de EPIs, salvo los casos de contacto social, en los que sí sería obligada la utilización de guantes y mascarillas.

Ahora bien, la obligación de protección del empresario no se agota con la simple dación del EPI adecuado, sino que el carácter "integral" de dicho deber exige la necesaria información y formación del trabajador en cuanto a su utilización. Siguiendo la línea marcada por los preceptos anteriormente citados (artículos 18 y 19 LPRL), el artículo 8.2 RD 773/1997 establece que "el empresario deberá informar a los trabajadores, previamente al uso de los equipos, de los riesgos contra los que les protegen, así como de las actividades u ocasiones en los que deben utilizarse" y de su forma de uso y mantenimiento. En consecuencia, el deber de protección integral exige al empresario no solo que proporcione los medios necesarios para la correcta protección del trabajador frente al riesgo valorado, sino que, también, se certifique que este está en posesión de todos los datos necesarios y completamente capacitado para el correcto uso de dichos materiales. Y, a tal fin, el empresario "organizará, en su caso, sesiones de entrenamiento para la utilización de equipos de protección individual"49. La capacitación del trabajador en el uso de este tipo de equipamientos resulta esencial, pues de este factor dependerá la eficacia del EPI facilitado y, por tanto, la protección de su vida e integridad física y moral. El artículo 19 LPRL regula la obligación del empresario de ofrecer una formación "teórica y práctica, suficiente y adecuada". Aquí, la cuestión consiste en determinar lo que se entiende, dentro de la utilización del EPI, por un aprendizaje completo que albergue todos los aspectos formativos. A estos efectos, debe advertirse que no existe ni reglamentación legal ni convencional que dé amparo al asunto planteado. En efecto, en el ordenamiento jurídico español no se prevé ningún desarrollo legislativo que, en atención al uso de equipamientos de protección, aclare el contenido mínimo del artículo 19 LPRL. Cierto es que la formación requerida al empresario, en la utilización de EPIs, no es de carácter general, sino que se adaptará al sector, tipo de empresa y puesto del trabajador. Con todo, esa falta de concreción de lo que debe entenderse por formación "adecuada y suficiente", debido a la ausencia de legislación legal complementaria, podría generar conflictos. En este sentido, mientras que en una determinada empresa puede ejecutarse de manera diligente el deber de formar a los trabajadores por la vía de imponerles la necesidad de participar e interactuar en cursos de aprendizaje completos, con parte teórica y práctica, y de superar un examen final; otra empresa puede optar por un curso más sencillo, que, pudiendo cumplir con los límites de contenido obligatorio, sin embargo, no proporcione el mismo nivel de conocimiento y práctica en el manejo de equipos de protección. En ambos casos, se podría considerar cumplida la obligación de los artículos 8 RD 773/1997 y 19 LPRL, pero, a nivel práctico, el conocimiento adquirido

${ }^{49}$ Artículo 8.3 RD 773/1997 
por ambas plantillas sería distinto. De ahí, la necesidad de precisar lo que debe entenderse por "formación suficiente y adecuada". A tal fin, resultaría conveniente establecer una normativa adicional de la LPRL que concretara, tanto respecto a la utilización de EPIS como a la formación de riesgos en general, el contenido del artículo 19 LPRL, para luego, partiendo de esos mínimos legales, poder configurar, en cada ámbito concreto, el plan de formación adecuado y suficiente.

En todo caso, este aprendizaje en la utilización de equipos de protección debe centrarse, siempre, en el riesgo concreto al que el trabajador se va a exponer. Así, la presencia del SARS-Cov-2 obliga al empresario a formar al trabajador en el correcto uso de EPIs respecto a la presencia de este virus en el ambiente laboral. A modo de ejemplo, no es suficiente un curso que -aun informando de la utilización de estos materiales- se refiera a riesgos diferentes a este virus, dado que aquel deberá hacer referencia estrictamente a la presencia de este agente biológico en el ámbito laboral. En otras palabras, el empresario, en el contexto del COVID-19, deberá ofrecer a sus trabajadores una formación adecuada, que, específicamente, se dirija a instruirlos tanto sobre la presencia de dicho virus en el entorno de trabajo como sobre el manejo de estos equipos de protección en relación con el mismo. En esta línea, se ha pronunciado numerosa jurisprudencia, estableciendo la responsabilidad empresarial en aquellos supuestos en los que el trabajador, aun recibiendo formación de carácter general, no se encontraba instruido respecto del específico peligro que podía implicar el desarrollo de su prestación laboral ${ }^{50}$.

Sobre este particular, la Ley sobre Infracciones y Sanciones en el Orden Social (en adelante, LISOS $)^{51}$, califica como sanción grave el incumplimiento del empresario de los derechos de información y formación de los trabajadores (artículos 12.11 y 12). Una tipificación que conlleva a la posibilidad de sanción mediante multa que puede ascender de dos mil cuarenta y seis euros a cuarenta mil novecientos ochenta y cinco euros (artículo 40.2 LISOS). Por tanto, este deber del empresario no puede considerarse como nimio ni baladí. El empleador que incumpla con los deberes de formación e información en el concreto uso de EPIs, aun cuando estos fueran aportados, infringe su obligación general de protección (artículo 14 LPRL), al considerar estos deberes como parte integrante fundamental de aquella, pudiendo el empresario ser sancionado por dicho comportamiento en los términos de esta ley.

\footnotetext{
${ }^{50}$ En este sentido se pronuncian la STSJ Madrid, Sala de lo Social, 508/2019, de 20 de junio (AS/2019/2085), que declara el recargo de prestaciones de la empresa afectada por omisión del deber de formar al trabajador específicamente en trabajos de altura; la STSJ Andalucía, Sala de lo Social, 2424/2018, de 25 de octubre (AS/2019/773), que falla en el mismo sentido, al quedar probada la falta de formación del trabajador en relación con puestos de trabajo vertical y al uso de los EPIs utilizados; y la STSJ Cantabria, Sala de lo Social, 580/2007, de 20 de junio (AS/2007/2796).

${ }^{51} \mathrm{El}$ actual texto refundido fue aprobado por el Real Decreto Legislativo 5/2000, de 4 de agosto.
} 
De manera complementaria a lo ya expuesto, en tercer lugar, el artículo 8 RD 664/1997 establece que "el empresario garantizará una vigilancia adecuada y específica de la salud de los trabajadores en relación con los riesgos por exposición a agentes biológicos", debiendo realizar un control antes de la exposición, durante la misma y ante un cambio de circunstancias (posible contagio de un trabajador). Así, las medidas de tipo organizativo e higiénico deben ser completadas con un constante y pertinente control de la salud de todo trabajador durante o con ocasión de la prestación laboral. Durante estos meses, ya son muchas las empresas que impusieron, por motivo del COVID-19 y para prevenir posibles infecciones, modelos de control del estado físico del trabajador al inicio de su jornada laboral, a lo largo de la misma y a su finalización. Sin embargo, debe precisarse que, de acuerdo con el artículo 22 LPRL, "esta vigilancia solo podrá ser llevada a cabo cuando el trabajador dé su consentimiento", salvaguardando, siempre, su derecho a la intimidad, a la dignidad de la persona y a la confidencialidad de toda la información relacionada con su estado de salud.

El consentimiento del trabajador se convierte, en este tipo de medidas, en el punto clave y fundamental en la ejecución del deber de protección del empresario. La obtención y manipulación de datos relativos a la salud es materia de especial cuidado y protección. Y, a tal fin, se dirige el artículo 22 LPRL y el Reglamento 2016/679 del Parlamento Europeo y del Consejo de 27 de abril de 2016, relativo a la protección de las personas físicas en lo que respecta al tratamiento de datos personales y la libre circulación de estos datos y por el que se deroga la Directiva 95/46/CE (en adelante, RGPD), al exigir, dicho Reglamento, el consentimiento del trabajador en la consecución y empleo de los mismos y al establecer que "el acceso a la información médica de carácter personal se limitará al personal médico y a las autoridades sanitarias (...), sin que pueda facilitarse al empresario o a otras personas sin consentimiento expreso del trabajador". De esta forma, se limita el poder del empleador sobre la gestión de las medidas preventivas, pues, acotando sus facultades, en cuanto al conocimiento del estado físico de sus trabajadores, se le obliga a lograr dicha información médica, esencial en el plan de prevención, mediante la venia de estos últimos.

Como se expuso al inicio de este artículo, el poder de organización y control del empresario no es ilimitado, sino que está acotado a la realidad de la relación laboral y a los derechos reconocidos al asalariado. En este sentido, cabe recordar que dicho poder quedar constreñido, inicialmente, por el respeto a la vida e integridad física y moral del trabajador (artículo $15 \mathrm{CE}$ ), configurando, a tal fin, el deber de protección del empresario (artículo 14 LPRL). Así, toda política empresarial o toda acción productiva debe partir de la salvaguarda del bienestar del trabajador como premisa básica y fundamental que, en todo caso, moldeará el ejercicio del derecho a la libertad de empresa (artículo $38 \mathrm{CE}$ ). 
Ahora bien, dentro de esta limitación de las facultades del empresario, la práctica de la propia obligación de prevención y protección supone someterse a nuevos límites: los derechos del trabajador a su dignidad e intimidad más personal (artículos 10 e $18 \mathrm{CE}$ ). Por tanto, toda política preventiva de riesgos laborales supone, por ella misma, un límite al poder de gestión empresarial, pero, incluso, la actividad empresarial ejecutiva de dicho plan preventivo encuentra el mismo tipo de límite.

En el contexto del COVID-19, la vigilancia de la salud de los trabajadores se ha convertido en una medida fundamental, con el claro objetivo de mantener y salvaguardar su salud y, finalmente, su vida e integridad física y moral. Con esta finalidad, se implantaron, en muchas empresas, controles de temperatura corporal o planes de urgencia a través de los cuales, en caso de un contagio, se alerta al resto de la plantilla de la infección de un trabajador (determinado e identificado). Al respecto, y de seguir la literalidad de la normativa anteriormente expuesta, la adopción de esta clase de medidas requeriría del consentimiento del trabajador y de la intervención de personal sanitario, que sería el responsable de la obtención y tratamiento de la información médica recabada. Sin embargo, en un contexto especial como el actual, en el que prima un claro interés público, se podrían encontrar "vías de escape" a través de las cuales el empresario sí podría imponer este tipo de medidas a todo trabajador, con independencia de que esté, o no, de acuerdo. A estos efectos, el considerando número 46 RGPD dispone que el tratamiento de información (sin consentimiento) debe considerarse lícito cuando en situaciones excepcionales, como una epidemia, prima un interés público o vital. O, lo que es lo mismo, si, como norma general, es necesaria la conformidad del trabajador para su sometimiento a este tipo de controles (que implican el conocimiento de datos personales íntimos relacionados con su salud), con carácter excepcional, en una situación como la provocada por el COVID-19, en la que prima un claro interés público de salubridad, se permitirá su adopción sin la aceptación de aquel, existiendo base legal en la que amparar tal comportamiento.

Por tanto, toda empresa que considere necesario controlar la temperatura corporal de sus trabajadores, como medida de vigilancia de la salud, podrá efectuar tal control sin que sea necesario contar con la conformidad de aquellos. La propia normativa reguladora de la protección de datos ofrece base para que, en situaciones como la actualmente vivida, se pueda obtener información médica, sin previo consentimiento del examinado, a fin de proteger el interés y la salud pública ${ }^{52}$. En este sentido, la Agencia española de protección

52 El artículo 6.1.d) RGPD establece que el tratamiento de datos, incluidos los médicos, sin previo consentimiento del afectado, solo será lícito cuando "sea necesario para proteger intereses vitales del interesado o de otra persona física"; precisando el artículo 9.2 del mismo texto legal, que dicho tratamiento estará permitido cuando "sea necesario por razones de interés público en el ámbito de la salud pública, 
de datos declaró que "las consideraciones relacionadas con la protección de datos dentro de los límites previstos por las leyes- no deberían utilizarse para obstaculizar o limitar la efectividad de las medidas que adopten las autoridades, especialmente las sanitarias, en la lucha contra la epidemia"53. En efecto, primando cuestiones superiores de vital protección, el acuerdo o no del trabajador (en cuanto a su sometimiento a este tipo de medidas de control) es irrelevante, no pudiendo aquel alegar derecho alguno en el que ampararse. Los controles periódicos del estado de salud de toda persona, ya sea trabajadora o no, se han convertido en una medida eficaz a fin de registrar y mantener el nivel de propagación del SARS-Cov-2, máxime en el ámbito laboral, en el que el contacto interpersonal (y, por tanto, la posibilidad de contagio) aumenta cuando es necesaria la interrelación para el desarrollo de las actividades profesionales. Así, es clara la procedencia de dichas medidas, cuya viabilidad se encuentra amparada por el propio RGPD.

En adición a lo anterior, en orden a legalizar el proceder del empresario, este podría amparar la adopción de este tipo de medidas en el cumplimiento de un deber legal. En efecto, el artículo 14 LPRL impone al empleador el deber integral de prevención y protección del trabajador ante todo posible peligro. Desde este punto de vista, siendo el COVID-19 más que un riesgo hipotético, y siendo proporcional la medida de control del estado de salud del trabajador al fin del deber impuesto, parece legal la adopción de estos controles. A este respecto, el artículo 6.1.c) RGPD establece que su tratamiento será lícito, sin requerimiento de conformidad previa, cuando sea "necesario para el cumplimiento de una obligación legal aplicable al responsable del tratamiento" (el empresario). En otras palabras, debiendo el empleador garantizar la vida e integridad física y moral de sus trabajadores y, por tanto, su salud frente a la posibilidad de contagio e infección por este agente biológico, aquel quedará exonerado de la obtención del consentimiento requerido cuando la propia obligación implique la necesidad de estos controles rutinarios del estado de salud de su plantilla. No obstante, esta dispensa de la necesidad de conformidad no implica, en ningún caso, la inaplicación de la Ley Orgánica 3/2015, de 5 de diciembre, de protección de datos personales y garantía de los derechos digitales (en adelante, LOPD), en cuanto a los principios que deben guiar la actuación del empresario, sus deberes como responsable del tratamiento y los derechos del trabajador como afectado.

como la protección frente a amenazas transfronterizas graves para la salud". Adicionalmente, el artículo 8 de la Ley Orgánica 3/2018, de 5 de diciembre, de Protección de datos personales y garantía de los derechos digitales (en adelante, LOPD), se remite a los términos del RGPD, a los efectos de considerar fundada la utilización de estos datos en cumplimiento de una misión de interés público.

53 Véase el Informe del gabinete jurídico de la "Agencia española de protección de Datos" N/REF: 0017/2020, en relación con los tratamientos de datos resultantes de la actual situación derivada de la extensión del virus COVID-19. Disponible en el siguiente enlace: https://www.aepd.es/es/documento/2020-0017.pdf 
En resumen, se exige que el tratamiento de esta información sea lícito, leal, transparente, adecuado y limitado a la finalidad pretendida (protección de la salud de los trabajadores). El empresario se encuentra legitimado para obtener aquellos datos de la salud que se consideren pertinentes y adecuados, a fin de prevenir un posible contagio por el agente biológico en cuestión, sin que este tratamiento pueda extenderse a cualquiera otra información que, aun conveniente, no sea necesaria para tal objetivo. El derecho a la protección de datos sigue aplicándose a estas situaciones, y como recuerda el RGPD (considerando 54), "el tratamiento de categorías especiales de datos personales, sin el consentimiento del interesado, puede ser necesario por razones de interés público en el ámbito de la salud pública". En todo caso, "ese tratamiento debe estar sujeto a medidas adecuadas y específicas, a fin de proteger los derechos y libertades de las personas físicas", no pudiendo estas razones públicas dar lugar a que terceros (como empresarios, compañías de seguros o entidades bancarias), "traten los datos personales con otros fines". En otras palabras, estando el empresario, legitimado para adoptar este tipo de medidas, deberá garantizar que la información obtenida sea tratada para el exclusivo fin para el que se le autoriza, garantizando la privacidad de dichos datos.

\section{Conclusiones}

El SARS-Cov-2 ha planteado un nuevo escenario lleno de incógnitas, en el que se hace necesario recuperar la economía y, consecuentemente, el nivel de actividad productiva. El mundo de las relaciones laborales, como eje de la recuperación, ha sufrido y está sufriendo la presencia de este agente biológico, provocando la necesidad de regular y actualizar políticas preventivas que protejan al trabajador de un posible contagio e infección, por o con ocasión del desarrollo de su prestación asalariada. En aras a la consecución de tal objetivo, los empleadores se han visto obligados a remodelar su estrategia preventiva, incorporando medidas de protección de tipo organizativo, higiénico y de control.

A estos efectos, son múltiples las sugerencias ofrecidas a las empresas, desde organismos públicos y mediante la fórmula de "guía" o "procedimiento", a través de los cuales se establecen criterios objetivos a cumplir, en aras al mantenimiento de un nivel de protección adecuado y ajustado a la situación actual de pandemia. Ahora bien, el solo cumplimiento de estas recomendaciones no agota el contenido del deber integral de protección del empresario, establecido en su máxima expresión en el artículo 14LPRL. Toda política preventiva, en tiempos de COVID-19, si bien debe tomar, como criterio orientativo, lo establecido en aquellas "guías" o "procedimientos"; sin embargo, debe ejecutar un análisis más profundo de la incidencia de dicho virus en el ambiente laboral y adoptar, en su virtud, la concreta medida preventiva respecto de cada puesto de trabajo. 
Se incide en la idea de que, el simple hecho de ofrecer al trabajador un concreto EPI $\mathrm{u}$ obligarle a teletrabajar como medida preventiva, sin ofrecerle la formación e información relativa a los riesgos que puede acarrear su uso incorrecto e inadecuado, no garantizan su derecho a la salud laboral.

De una u otra forma, la pandemia creada por el COVID-19 ha puesto en entredicho la regulación contenida en la LPRL en cuanto a su generalidad de conceptos, imprecisiones y su inadaptación a la nueva realidad laboral. El régimen del trabajo a distancia, cuya incidencia ha aumentado como consecuencia de esta pandemia, es uno de estos ejemplos. La configuración de la normativa preventiva clásica, basada en el modelo de trabajo presencial sometido a un estricto horario laboral, no se ajusta a las nuevas formas de trabajo descentralizadas, en las que la flexibilidad (tanto locativa como temporal) es un rasgo característico fundamental. Con el RD 28/2020 se ha tenido la oportunidad de suplir esta deficiencia, pero, sin embargo, se vuelve a incurrir en el mismo error al realizar una remisión generaliza (aun, con ciertas especialidades irrelevantes) a la LPRL.

La nueva realidad social, ya sea como consecuencia de la pandemia o de la digitalización e introducción de novedosa tecnología en la prestación de servicios, está requiriendo una nueva regulación preventiva que se adapte a las nuevas exigencias. La aparición de nuevos peligros en el entorno laboral, independientemente de la causa de su origen, reclama la articulación de una nueva regulación que haga frente al nuevo panorama, mostrándose flexible en su articulación, pero estableciendo, en todo caso, el contenido y los puntos básicos a tratar.

\section{Bibliografía}

CASAS BAAMONDE, María. Emilia: "Derecho público y salud laboral: el régimen jurídico sancionador", Derecho y salud, vol. 4, núm. 1, 1996, pp. 91-124.

CRUZ VILLALÓN, Jesús: "Teletrabajo y coronavirus: de la emergencia a la permanencia”, Derecho de las Relaciones Laborales, núm. 4, 2020, pp. 406-417.

DE LAS HERAS GARCÍA, Aranzazu, "Análisis de la nueva regulación del trabajo a distancia”, Revista de Trabajo y Seguridad Social. CEF, núm. 452, 2020, pp. 171-193.

DÍAZ BERNARDO, Luís, "Extensión del deber de protección del empresario frente a riesgos biológicos en actuaciones excluidas del ámbito de aplicación de la Ley 31/1995, de 8 de noviembre, de prevención de riesgos laborales. STSJ Asturias 11 de mayo de 2012”, Revista doctrinal Aranzadi Social, núm.50, 2012, pp. 1-9 (BIB 2012/3056). 
ESQUERRA ESCUDERO, Luís, "Contenido y extensión del artículo 15. Incidencia en el ámbito laboral”, en VV.AA., ESQUERRA ESCUDERO, Luís (coordinador), RIVAS VALLEJO, Pilar, y AGUSTÍ MARAGALL, Joan, Estudios sobre el derecho a la vida e integridad física y moral en el ámbito laboral, Barcelona, Atelier Libros Jurídicos, 2010, p. 15-155.

FERNÁNDEZ AVILÉS, José Antonio, “Es suficiente este derecho laboral excepcional "por aluviones" frente a la pandemia del COVID-19?", Revista de Trabajo y de la seguridad social, abril 2020, núm. 445, pp. 7-26.

GARCÍA NINET, José Ignacio, y VICENTE PALACIO, María Arántzazu: "Derechos y obligaciones del empresario", en VV.AA., GARCÍA NINET, José Ignacio (director) y BARCELÓ FERNÁNDEZ, Jesús, y MONERO CÁLIZ, Susana, Manual de prevención de riesgos laborales, Barcelona, Ateliaer Libros Jurídicos, 2017, pp. 131-147.

GONZÁLEZ ORTEGA, Santiago, "La seguridad e higiene en el trabajo en la Constitución”, Revista de política social, núm. 121, 1979, p. 200-226.

IGARTUA MIRÓ, María Teresa, “La prevención de riesgos laborales en la empresa: el empresario deudor de la seguridad” y “Obligaciones específicas (I): los aspectos centrales del sistema”, Sistema de prevención de riesgos laborales, Madrid, Editorial Tecnos, 2011, p.123-176.

LÓPEZ INSUA, Belén del Mar, "derecho a la vida e integridad física”, en VV.AA., MONEREO PÉREZ, José Luís, VILA TIERNO, Francisco. y ÁLVAREZ CORTES, Juan Carlos (directores) y LÓPEZ INSUA, Belén del Mar, Derechos laborales fundamentales específicos, Granada, Comares, 2020, pp. 501-537.

LOUSADA AROCHENA, Fernando y RON LATAS, Ricardo Pedro.: "Una mirada periférica al teletrabajo, en el trabajo a domicilio y el trabajo a distancia en el derecho español", en VV.AA. MELLA MÉNDEZ, Lourdes y VILLALBA SÁNCHEZ, Alicia, Trabajo a distancia y teletrabajo. Estudios sobre su régimen jurídico en el derecho español y comparado, Pamplona, Aranzadi, 2015, pp. 31- 45

LOZANO LARES, Francisco, "El contenido y alcance de la obligación general de seguridad y salud”, Trabajo y Derecho, núm. 70, 2020, pp. 1-26.

MARTÍN HERNÁNDEZ, María Luisa, "El derecho de los trabajadores a la seguridad y salud en el trabajo", Madrid, Consejo Económico y Social, 2006. 
MELLA MÉNDEZ, Lourdes: "Configuración general del trabajo a distancia en el derecho español”, en VV.AA. MELLA MÉNDEZ, Lourdes (directora), SIERRA BENÍTEZ, Esperanza Macarena, CARDONA RUBET, María Belén, y CABEZA PEREIRA, Jaime, El teletrabajo en España: aspectos teóricos-prácticos de interés, Madrid, La Ley Wolters Kluwer, 2017, pp. 19-82.

MELLA MÉNDEZ, Lourdes: "La seguridad y salud en el teletrabajo", en VV.AA. MELLA MÉNDEZ, Lourdes y VILLALBA SÁNCHEZ, Alicia, Trabajo a distancia y teletrabajo. Estudios sobre su régimen jurídico en el derecho español y comparado, Pamplona, Aranzadi, 2015, pp. 178-204.

PALOMEQUE LÓPEZ, Manuel Carlos, "El deber del empresario de protección de los trabajadores, frente a los riesgos laborales", Revista general del Derecho del Trabajo y de la Seguridad social, núm. 8, 2005, p. 4. Disponible en el siguiente enlace:https://www.iustel.com/v2/revistas/detalle_revista.asp?id_noticia=403831\&d=1 $\underline{\&}$

PALOMEQUE LÓPEZ, Manuel Carlos, "El derecho constitucional del trabajador a la seguridad en el trabajo", Actualidad Laboral, núm. 1, 1992, pp. 37-44.

RODRÍGUEZ CRESPO, María José, "La necesaria observancia de los derechos fundamentales en las relaciones laborales como límite inexcusable del poder de dirección empresarial", IUSLabor, núm. 2, 2018, pp. 173-185.

RODRÍGUEZ ESCANCIANO, Susana.: "Luces y sombras del teletrabajo a domicilio en una nueva economía de bajo contacto", Revista Española de Derecho del Trabajo, núm. 233, 2020, pp. 145-202.

SALA FRANCO, Tomás, "El deber empresarial de protección del trabajador en materia de seguridad y salud laboral”, Derecho y salud, vol. 4, núm. 1, 1996, pp. 7-26.

SAN MARTÍN, MAZZUCCONI, Carolina, "Derecho a la Vida e integridad personal; la seguridad y salud en el trabajo", Revista del Ministerio de Empleo y Seguridad Social, núm. 108, 2014, pp. 91-108.

THIBAULT ARANDA, Javier, "Definición y Tipología", El teletrabajo. Análisis jurídico-laboral, Madrid, Consejo Económico Social, 2001, pp. 23-38. 
TORRES GARCÍA, Bárbara, "Sobre la regulación legal de la desconexión digital en España: valoración crítica", Revista internacional y comparada de relaciones laborales y derecho del empleo, vol. 8, núm. 1, 2020, pp. 239-262.

TORRES GARCÍA, Bárbara: "Derecho a la salud y seguridad en el empleo y su naturaleza de derecho fundamental en el ordenamiento español", texto original (en prensa).

Otros documentos

ORGANIZACIÓN MUNDIAL DE LA SALUD (OMS): "Informe anual sobre la preparación mundial para las emergencias sanitarias", de septiembre de 2019. Disponible en el siguiente enlace: https://apps.who.int/gpmb/assets/annual_report/GPMB_Annual_Report_Spanish.pdf

ORGANIZACIÓN MUNDIAL DE LA SALUD (OMS): "Reglamento Sanitario Internacional (2005): $2^{\circ}$ Edición". Disponible en el siguiente enlace: https://www.who.int/ihr/IHR_2005_es.pdf

ORGANIZACIÓN MUNDIAL DE LA SALUD (OMS): “Thematic Paper on the Status of Country Preparedness", de 25 de septiembre de 2019. Disponible en el siguiente enlace: https://apps.who.int/gpmb/assets/thematic_papers/tr-2.pdf

ORGANIZACIÓN MUNDIAL DE LA SALUD (OMS): “COVID-19 and the world of work: Impact and policy responses", de 18 de marzo de 2020. Disponible en el siguiente enlace: $\quad$ https://www.ilo.org/wcmsp5/groups/public/--dgreportdcomm/documents/briefingnote/wcms_738753.pdf

ORGANIZACIÓN INTERNACIONAL DEL TRABAJO (OIT): "Safe and healthy return to work during COVID-19 pandemic". Disponible en el siguiente enlace: https://www.ilo.org/wcmsp5/groups/public/---ed_protect/---protrav/--safework/documents/briefingnote/wcms_745549.pdf

ORGANIZACIÓN INTERNACIONAL DEL TRABAJO (OIT): "El teletrabajo durante la pandemia del COVID-19 y después de ella. Guía Práctica”. Disponible en el siguiente enlace: $\quad$ https://www.ilo.org/wcmsp5/groups/public/---ed_protect/---protrav/--travail/documents/publication/wcms_758007.pdf

DIRECCIÓN GENERAL DE LA SALUD PÚBLICA, CALIDAD E INNOVACIÓN: "Procedimientos de actuación para los servicios de prevención de riesgos laborales frente 
a la exposición al SARS-Cov-2, de 7 de octubre de 2020". Disponible en el siguiente enlace:

https://www.mscbs.gob.es/profesionales/saludPublica/ccayes/alertasActual/nCov/docu mentos/Proteccion_Trabajadores_SARS-CoV-2.pdf

INSTITUTO DE SEGURIDADE E SAÚDE LABORAL DE GALICIA (ISSGA): “Guía básica ISSGA para la elaboración del plan de contingencias". Disponible en el siguiente enlace:

http://issga.xunta.gal/export/sites/default/recursos/descargas/documentacion/publicacion s/Covid_empresas_CASTELLANO.pdf

INSTITUTO VASCO DE SEGURIDAD Y SALUD LABORALES (OSALAM): “Guía para la elaboración del plan de contingencia”. Disponible en el siguiente enlace: https://www.osalan.euskadi.eus/contenidos/informacion/procedimiento_coronavirus/es def/adjuntos/plan-contingencia-covid-es.pdf

MINISTERIO DE TRABAJO Y ECONOMÍA SOCIAL: “Guía para la actuación en el ámbito laboral en relación al nuevo Coronavirus". Disponible en el siguiente enlace: http://www.mites.gob.es/ficheros/ministerio/inicio_destacados/Gua_Definitiva.pdf

MINISTERIO DE TRABAJO Y ECONOMÍA SOCIAL: "Criterio operativo $\mathrm{n}^{\circ}$ 102/2020, sobre medidas y actuaciones de la Inspección de Trabajo y Seguridad Social relativas a situaciones derivadas del nuevo Coronavirus (SARS-Cov-2)". Disponible en el siguiente enlace: https://www.fespugtmadrid.es/wp-content/uploads/2020/03/Cir-03520-bis-Criterio-operativo-coronavirus.pdf 